\title{
LA IMAGEN DE LOS JUDÍOS EN LOS SERMONES DE BARTOMEU CATANY, O.F.M. (C. 1380-1462)*
}

\author{
POR \\ Oriol CATALÁn CASANOVA ${ }^{1}$ \\ Universitat Pompeu Fabra
}

\begin{abstract}
RESUMEN
El artículo amplía el tradicional análisis político de los sermones del franciscano Bartomeu Catany (c. 1380-1462) con un análisis de la imagen que presentan de los judíos, las principales fuentes utilizadas, su relación con la literatura antijudía y anticonversa del siglo xv y su papel en la creación de un sentimiento de odio hacia los judíos y conversos, en el contexto de los conflictos de la Mallorca de mediados del siglo xv y de la persecución y expulsión de los judíos de los reinos hispánicos.
\end{abstract}

PALABRAS CLAVE: Bartomeu Catany; predicación medieval; predicación franciscana; antisemitismo; conversos.

\section{THE IMAGE OF THE JEWS IN THE SERMONS OF BARTOMEU CATANY, O.F.M. (C. 1380-1462)}

\section{ABSTRACT}

This article widens the traditional political analysis of the sermons by the Franciscan friar Bartomeu Catany (c. 1380-1462) by showing the image of the Jews that the sermons transmitted, the sources used, the relation of these sermons with the antiJewish literature in 15th century, and their role in the evolution of hatred in the context of xvth-century Majorcan society and the persecution and expulsion of the Jews from the Hispanic Kingdoms.

KEY WORDS: Bartomeu Catany; Medieval Sermons; Franciscan preaching; Antisemitism; conversos.

COMO CITAR ESTE ARTículo / CitATION: Catalán Casanova, O. 2017 «La imagen de los judíos en los sermones de Bartomeu Catany, O.F.M. (c. 1380-1462)». Hispania Sacra 69, 140: 505-520. doi: 10.3989/hs.2017.031

\author{
Recibido/Received 24-11-2015 \\ Aceptado/Accepted 26-11-2015
}

Bartomeu Catany, O.F.M. (c. 1380-1462) ha sido objeto recientemente de un volumen monográfico en el que se estudia principalmente su biografía y las ideas políticas de sus sermones. ${ }^{2}$ Además de ser un destacado predicador ${ }^{3}$,

* Este artículo forma parte del proyecto FFI2015-63659-C2-2-P del Ministerio de Economía y Competitividad: «Estudios interdisciplinarios y comparativos sobre identidades religiosas, (trans) culturales y de género en la península ibérica y el Mediterráneo medieval y moderno", que tiene como investigador principal a la Dra. Linda G. Jones, de la Universitat Pompeu Fabra de Barcelona.

1 oriol.catalan@upf.edu / ORCID iD: http://orcid.org/0000-0003 $-0301-3686$

2 Morro Veny 2008. La ausencia de notas del libro se puede a veces reparar en Morro Veny 1997. Los libros fundamentales anteriores son: Furió 1851; Cuadrado 1847.

3 Además de los sermones conservados, hay noticias de un sermón para el Viernes Santo de 1444 en la Catedral de Mallorca, interesante por mezclar predicación y teatro. Vid. Llompart 1988; Massip 2007. fundó conventos observantes en Sóller, Mahón y Palma, jugó un papel relevante en la Revolta Forana (1450-3) y unificó los hospitales de Mallorca en un Hospital General. ${ }^{4}$

Su prestigio como predicador es incuestionable. Entre 1420 y 1455 predicó más de veinte Cuaresmas en la Catedral de Palma. ${ }^{5}$ Además, fue requerido por la reina María para predicar en Barcelona, donde pasó un tiempo indeterminado entre 1451 y 1454, recibiendo una alta valoración por su predicación. ${ }^{6}$

Después de su estancia en Barcelona, todavía recibió un encargo de mediación de parte de Pío II, pero en general su

4 Morro Veny 2008: 117-39.

5 Morro Veny 2008: 43-6.

6 Morro Veny 2008: 41-2, 105-6. La carta de la Reina María a los jurados de Mallorca, en Arxiu Històric de la Ciutat de Barcelona, Lletres closes, VI-18, f. 127v. 
presencia pública y predicación parecen disminuir debido a su avanzada edad. ${ }^{7}$

Aunque también tuvo períodos eremíticos, el aspecto en el que más destacó Bartomeu Catany fue su implicación en la sociedad mallorquina. En alguno de sus sermones critica explícitamente a los malos gobernantes. ${ }^{8}$ Además, en 1451 intentó frenar, aunque sin mucho acierto ni éxito, la intransigencia del gobernador Berenguer d'Olms tras la Revolta Forana. ${ }^{9}$

\section{LOS SERMONES: DATACIÓN Y CARACTERÍSTICAS}

Los sermones de Bartomeu Catany han pasado casi desapercibidos. ${ }^{10}$ El manuscrito 25 del Archivo del Estado en Mallorca está formado por 148 folios que contienen 159 sermones de tempore escritos por una misma mano a doble columna y divididos en dos grandes apartados:

- f. 1r. Sermones dominicales tocius anni. 127 sermones, de los cuales 47 de Cuaresma.

-f. 133ra. Incipiunt lecciones feriales quadragesime. La mayoría dedicados a la confesión. Contiene 32 sermones de Cuaresma.

Aunque a veces hay más de un sermón para cada fecha, el sermonario no contiene todos los sermones del ciclo litúrgico. En algún caso esto se debe a la pérdida de folios (saltos de 10v. a 23r., de 66v. a 73r. y de 82v. a 95r.).

La mayor parte de los sermones corresponden a los ciclos de Adviento y Cuaresma, que contienen varios ciclos de sermones para cada período litúrgico. ${ }^{11}$ En ocasiones se altera el orden litúrgico de los sermones. Los sermones del Domingo de Pasión, por ejemplo (39r., 47r., 55r., 60v., 65v., 76r., 80vb), están situados antes de los de Domingo de Ramos, Jueves y Viernes Santo.

Todos los sermones están redactados en latín, aunque ocasionalmente se encuentra alguna división del texto, enumeración o pequeña frase en catalán, ${ }^{12}$ lo cual sugiere que los sermones fueron predicados en esta lengua.

La mayoría de los sermones siguen una misma estructura:

- No se da el thema al inicio, pero suele aparecer en el cuerpo del sermón.

- Introducción al sermón seguido del rezo del Ave María.

- Introducción al thema, que acaba con la frase «Que fuere verba thematis. In quibus sunt duo principaliter».

- La división del sermón se hace habitualmente en dos partes.

- Cada división viene subdividida en tres o cuatro subdivisiones, introducidas por la frase Sed ad maiorem declarationem huius prime (secundae) partis...

\footnotetext{
7 Morro Veny 2008: 107-16.

8 Morro Veny 2008: 45, 49-54.

9 Morro Veny 2008: 99-103.

10 A excepción de los tres dedicados a San Francisco publicados en: Algaida 1931: 408-421. Los sermones se encuentran en los ms. 25 y 26 del Archivo del Estado en Palma de Mallorca (BPEM).

11 Hay tres ciclos de sermones de Adviento y siete ciclos de Cuaresma, y todavía falta un octavo ciclo por pérdida de los folios 67 a 72.

12 50v., 51r.-v., 74v., 78v., 79r., 96r., 107v., 108v., 113v., 115v, 118r., $119 r ., 120 v$.
}

Como apuntaba Hillgarth, los sermones fueron compilados tras la muerte de Catany por un discípulo suyo. ${ }^{13}$ Aunque no hay datación explícita en el sermonario, algunos sermones ofrecen datos a partir de los que podemos conocer su fecha de redacción:

Et hoc hodie sunt conpleti mille quadringenti et sexaginta et sex anni et incipit M CCCC LXVIlus, in quo die fuerunt multa signa ostensa in huius pueri nativitate. ${ }^{14}$ fecha:

Más adelante, hablando de la Epifanía, aparece otra

$$
\text { Hodie sunt M CCCC L XV (anni)...15 }
$$

Y en referencia al juicio de Jesús, podemos leer:

Hodie sunt mille CCCC XXXIIo anni quod concluserunt concilium ut interficerent Christum. ${ }^{16}$

Estas citas sugieren la redacción del sermonario hacia 1465-7. En otro lugar, sin embargo, se dice:

Hodie sunt mille et CCCCXII ani quibus omnia ista in hac hora disponebantur ut fierent et de Christo facerent iudicium. ${ }^{17}$

Esto sugiere como fecha $1412+33=1445$, justo 20 años anteriores a las otras referencias. Aunque se puede tratar de un error de escritura (1412 en lugar de 1432), la referencia a 1445 podría ser una fecha no actualizada por el compilador y tratarse de la fecha de elaboración del sermón o de su posible predicación.

En cualquier caso, los sermones parecen redactados o predicados después de la conversión de la comunidad hebrea de Mallorca en $1435^{18}$ y dirigidos a la comunidad cristiana que incluía ya a los conversos, aunque es posible que algún sermón sea anterior a estas fechas. Los sermones con referencias políticas y críticas al mal gobierno podrían ser de la época de la Revolta o incluso posteriores. La compilación de los sermones sería posterior a la muerte de Catany. ${ }^{19}$

En cuanto a la tipología de sermón, se trata de una compilación de sermones «facti et compositi per reverendum patrem... Bartholomeum Catany ${ }^{20} \mathrm{El}$ hecho de realizar la compilación después de su muerte sugiere la voluntad de tener un modelo para su uso en la isla, seguramente debido a la fama de santidad de la que gozó Catany en su época.

13 Hillgarth 1991: 212, nota 152. Aunque no justifica la afirmación, seguramente procede del íncipit del sermonario (f. 1r.), en el que se lee: "Incipiunt sermones dominicales tocius anni facti et compositi per reverendum patrem ac magistrum meum magister Bartholomeus Catany ordinis minorum». No compartimos la opinión de Veny, quien opina que el manuscrito es autógrafo de Catany.

14 BPEM, ms. 25, f. 23v.

15 BPEM, ms. 25, f. 27v.

16 BPEM, ms. 25, f. 47r.

17 BPEM, ms. 25, f. 82r.

18 Braunstein 1976: 93-95, nota 16. Una explicación de los hechos en Riera 1989 y 1993: 81. El documento fundamental está editado en Llompart y Riera 1979-80.

19 Morro Veny (2008: 115 y 142) da como fecha de muerte 1462 sin aportar fuentes. Furió 1851: 169 da la misma fecha a partir de un manuscrito de Joan Amadeu Bauçà, base de todos los estudios posteriores. Damos la fecha, que también aparece en la tumba del predicador, como correcta.

20 El incipit (f. 1r.) habla de sermones. 
Algunas características de los sermones como la repetición de frases para los inicios de las diferentes partes del sermón, indican una estandarización, ya sea por parte del predicador o del compilador de los sermones y una voluntad de servir de modelo a otros predicadores.

En cualquier caso, el sermonario no parece haber tenido mucha influencia fuera del ámbito del convento franciscano de Mallorca. El poco éxito del sermonario se puede deber al gran número de referencias políticas, cosa que muchos Ars praedicandi censuraban, especialmente en los sermones ad populum.

Contexto de los Sermones: judíos y CONVERSOS EN MALLORCA

La situación de la comunidad judía de Mallorca era, con algunas peculiaridades, similar a la que vivían las comunidades peninsulares. ${ }^{21}$ Ya en 1331 el obispo de Mallorca Guiu Terrena se quejaba de la tolerancia de Jaime III hacia los judíos, a los que acusaba de idólatras, e intentaba impedir la construcción de una sinagoga en Palma. ${ }^{22}$

A mediados de siglo xIV los judíos ya eran obligados a asistir a sermones cristianos, muchas veces realizados por conversos como Jimeno Pérez de Tudela, Pere de Grau (que causaba escándalo en la isla en 1351) y Nicolau de Grau. En 1373 hubo un altercado violento antijudío. Los disturbios y ataques de 1391 destruyeron el call, que nunca recuperó el esplendor anterior. ${ }^{23}$ Como consecuencia de los ataques, apareció una comunidad de conversos que se integró en la cofradía de San Miguel, fundada en 1404. En 1413, el rey Fernando aprobaba unas Constitutiones contra iudaeos regni Maioricarum que intentaban separar conversos y judíos. $^{24}$

Estas Constitutiones vienen fechadas el 20 de marzo, varios meses antes de la visita de Vicente Ferrer a Mallorca, pero fueron publicadas en Mallorca días después (28 de septiembre) de la llegada del dominico a la isla (1 de septiembre)..$^{25}$ Braunstein considera la visita de Ferrer clave en la decadencia final de la judería, aunque su conversión definitiva tardara todavía más de veinte años. ${ }^{26}$

Vicente Ferrer permaneció en Mallorca hasta enero de 1314. ${ }^{27}$ No hay constancia de las consecuencias de la predicación de Vicente Ferrer en la isla, pero en 1416, "nostre sant Pare ha revocades totes les ordinacions que lo dit Senyor Bisbe havia fetes del temps que vench en Mallorques ab Mestre Vincent Ferrer ${ }^{28}$.

Tampoco sabemos si Bartomeu Catany estaba en Mallorca por esas fechas o si vio en algún momento predicar a Vicente Ferrer. En esa época contaría Catany más de 30

\footnotetext{
21 Abulafia 1992.

22 Llompart y Riera 1979-1980.

23 Maiz Chacón 2010: 55, 76, 150; Baer 1981: 371, 404.

24 Villanueva 1852: 258-264.

25 Pérez Martínez 1955: 40.

26 Braunstein 1976.
}

27 Para la visita del dominico, además de Pérez Martínez 1955, véase Rosselló Lliteras 1987. Los sermones de Mallorca se encuentran en el manuscrito de Aviñón, Musée Calvet, ms. 610, f. 68-172. También fue predicado en Mallorca el sermón editado por Sanchis Sivera (ed.) 1934. Sermons. Volumen II. Barcelona: Barcino: 243-259.

28 Villanueva 1852: 51. años, por lo que es probable que estuviese ya ordenado y residiese en el convento franciscano de la isla, pero esta fase de su vida está poco documentada.

El 1435 la comunidad judía de Mallorca fue obligada a convertirse en bloque, aunque quizás sobrevivió algún reducto judío en la isla. ${ }^{29}$ De hecho, las restricciones a la actividad de los judíos continuaron. En el Llibre de contemplació de Francesc Prats, escrito hacia 1485, aún aparecen insultos a los judíos ${ }^{30}$, de un tono similar a los de la memoria enviada por Bartomeu Caldentey al gobernador para impedir al judío Isaac trabajar como médico en $1488 .^{31}$

En 1488 llegaba a Mallorca la Inquisición real, y una de las primeras actuaciones que hizo fue la reconciliación de cientos de conversos a cambio de un fuerte pago monetario. Tres años más tarde hubo una segunda reconciliación. ${ }^{32}$

Los investigadores de la sociedad mallorquina del siglo $\mathrm{XV}$ creen que, más allá de forzar a los judíos a bautizarse, pocos esfuerzos se hicieron para la enseñanza de la doctrina a los neófitos. ${ }^{33}$

\section{LOS JUDÍOS EN LOS SERMONES}

El tema judío no es el principal en los sermones estudiados. En muchos sermones no aparece y en otros lo hace de forma puntual. Solamente en algunos es un elemento estructurador del sermón o aparece repetidamente:

- 2r.: Dominica III $\underline{a}$ de Adventu.

-23v. In die sancti Stephani.

- 39r. Dominica de Passione.

- 47r. Dominica de Passione.

- 52r. Dominica prima in quadragesima.

- 56v. Dominica in ramis palmarum.

- 147r. Feria IIII $\underline{a}$ Dominica de Passione.

La imagen que dan de los judíos los sermones de Bartomeu Catany es la predominante en el contexto de la polémica antijudía. La acusación de deicidio es la más antigua y repetida hacia los judíos, aunque no es la más habitual en estos sermones (40r., 56v., 148r.). ${ }^{34}$ Las acusaciones más repetidas son las referentes a envidia, malicia, ceguera, perfidia y contumacia (2r., 6r., 9r., 23v., 24r., 38r., 38v., 45v.,

29 Roth 2002: 261.

30 Prats 1985: 41: «maliciosos jueus»; 63: «Fills d’Abraham!, per nom e generació, e no per fe y obres, perquè oblidau la Scriptura e Ley vostra»; 64: "la insaciable furor dels sacrílegs e fills de la diabólica Sinagoga no són coneguts cessar ne pendre repòs; ans, demostrant la pertinacia e obstinada nequicia, insten que muyra, e tanta és la ira e indignació, que no té loch pietat e misericordia. De hon, vociferant, los altres a cridar exciten: Sia crucificat! Sia crucificat»; 67: «la sobreabundant malícia dels juheus pren doble força, tals paraules hoint».

31 Riera 1989: 233-235. La demanda de Bartomeu Caldentey, Francesc Prats, Joan Domènech y Risso contiene citas del Scrutinium Scripturarum, del Fortalitium fidei y del Zelus Christi, y refleja una actitud muy agresiva hacia los judíos. Está editada en Boletín de la Sociedad Arqueológica Luliana 9, 1901-1902. Palma de Mallorca: 284-288. No está claro si Isaac era habitante de Mallorca o se encontraba de paso en la isla.

32 Santamaría 1997: 235-239.

33 Santamaría 1955: 188.

34 Dado el elevado número de citas breves, se transcriben en apéndice. Todas se refieren al ms. 25 del Archivo Público Estatal de Palma de Mallorca. 
$47 r ., 47 v ., 48 r ., 48 v ., 49 v ., 55 r ., 56 v ., 57 r ., 59 v ., 61 v ., 77 r ., ~ 81 v .$, $140 r ., 141 r ., 145 v ., 146 v ., 147 r ., 147 v$.$) .$

Los argumentos subían a veces de tono y se convertían en acusaciones de pacto con el diablo o en comparaciones con animales. Estas acusaciones, más allá del insulto, implicaban una desvalorización de la comunidad judía y una pérdida de la personalidad jurídica que facilitaban y legitimaban la violencia.

En época de Catany, las tradicionales acusaciones de pacto entre judíos y el diablo se estaban actualizando en obras como el Fortalitium fidei de Alonso de Espina ${ }^{35}$ o el Alboraique. ${ }^{36}$ En el primero de ellos, Alonso de Espina, también franciscano observante y predicador, relaciona explícitamente el judaísmo con el demonio:

Nam dicit Rabi Salomon quod ante creationem Eve, Adam habuit uxorem nomine Lilis et quod fuit ante Adam pro ligno vetito excomunicatus per triginta annos in quibus ex uxore Lilit genuit tamen demones. Item dicitur in libro Canedrin quod illi CXXX anni spacii quod fuit ex quo natus fuit Cayn et Abel quousque natus fuit Seth, quod durante illo tempore non faciebat Adam nisi generare spiritus malignos et ipsa pariebat eos. Ex quibus manifeste concluditur intentum, scilicet, quod demones et maligni spiritus sunt fratres iudeorum et non aliorum homini quia ipsi soli ponunt hanc doctrinam infamantes patrem suum Adam. Et ideo confusionem que ex infamatione patris sequitur in premium reportant. Unde merito dixit eis Christus cum se iactarent filios Abrahe et esent contradicentes in operibus: "Vos ex patre dyabolo estis», lohanes VIII. Ex quo sequitur quod iudei non solum sunt fratres demonum ut convincitur ex eorum doctrina, sed etiam filii dyaboli ex doctrina filii Dei. ${ }^{37}$

La demonización de los judíos apenas aparece explícitamente en los sermones (147v.). A veces, sin embargo, se desprende de la explicación que da el predicador de los vicios atribuidos a los judíos. Es el caso de la envidia, asociada por Catany a los judíos (120v., 147v.). En algunos casos, se hace referencia al pacto de los judíos con el Anticristo (5r.).

El miedo al Anticristo se remonta a obras como el Compendium theologicae veritatis de Hugo Repellin, y a una anterior Expositio in Apocalipsim de Haimo de Auxerre (Catany utiliza una cita común a ambos, f. 5r.) y evolucionó en los siglos XIV y XV. La identificación del Anticristo con el Mesías judío y el pacto entre Anticristo y judíos eran tópicos que tuvieron un importante papel en el antijudaísmo bajomedieval. ${ }^{38}$

Paralelamente a la acusación de pacto con el diablo y el Anticristo, se formó y extendió la opinión de la impureza de sangre de judíos y conversos. La mezcla de estos argumentos acabó conformando una opinión según la cual las características étnicas y religiosas no desaparecían tras la conversión. ${ }^{39}$

35 Espina 1485; Meyuhas Ginio 1998.

36 Lazar, edita el manuscrito Paris BNF, esp. 356. Bravo Lledó y Gómez Vozmediado 1999, recoge la impresión de Sevilla de 1545. Sobre el Alborayque, véase Gitlitz 1992.

37 Espina Liber III, consideratio secunda, f. XLIII. Sobre el tema, vid. Monsalvo Antón 1994 y 2012.

38 Gow 1995: 100 y 110.

39 Nirenberg 2008: 80 y 2000.
Las conversiones significaron un desafío a la identidad de las sociedades de los reinos hispánicos, tanto de judíos como de cristianos $^{40}$, creando un nuevo grupo social que compartía religiosidad y tradiciones de los dos grupos. Las fronteras culturales y religiosas se difuminaron. ${ }^{41}$

En un primer momento, el cristianismo concedió a los conversos los mismos derechos que los cristianos. Un decreto de la reina María de Aragón en 1433 y un decreto del Concilio de Basilea en 1434 defendían todavía la integración con plenitud de derechos. ${ }^{42}$

Poco después el criterio empezó a cambiar. Los conversos podían trabajar en oficios y aspirar a cargos que tenían prohibidos como judíos. Además, la conversión había hecho legales los matrimonios de conversos con cristianos, y muchos cristianos no podían aceptar la convivencia con aquellos que poco antes eran demonizados, perseguidos e insultados. Hacia 1430-40 aparecen las primeras polémicas anticonversas y las primeras defensas de pureza de sangre. La sociedad cristiana empezó a ver a los nuevos cristianos como falsos conversos que no habían perdido ni la malicia ni el odio hacia el cristianismo que se atribuía a los judíos. ${ }^{43}$

Los sermones de Bartomeu Catany se inscriben en este proceso. Catany afirma que los judíos están infectados por una malicia demoniaca que, implícitamente, no se cura con el bautismo, sino únicamente con la sangre de Cristo (76r.). Catany utiliza la palabra "triaca», antídoto contra venenos hecho a base de diversas plantas, que se podía disolver en vino para su administración.

El trato del judaísmo como enfermedad infecciosa no era novedoso. En el caso de Mallorca, hallamos referencias en las Constitutiones contra Judeos regni Maioricarum:

Statui la sancta mare eclesia los dits juheus en apartat loch habitar é viure, per ço encara que llur fetidat é inmundicia en los dits christians no engendrassen infeccions, é llurs errors no corrompessem la puritat de aquells. $^{44}$

Más novedoso era considerar la infección de origen diabólico. En este sentido, los sermones de Catany son contemporáneos del Fortalitium fidei, que como hemos visto trataba a los judíos como hijos del demonio y asimilados al Anticristo. Siguiendo esta lógica, los conversos, como miembros del linaje judío, no podían ser considerados nunca como verdaderos cristianos. ${ }^{45}$

Entendiendo que por "fideles» Catany se refiere a los conversos, parece insinuar que el bautismo no bastaba para purificar a los conversos. Esta idea aparece en alguna otra ocasión (120r., 144r.). Aunque el argumento queda ambiguo, se trata de un razonamiento muy poco habitual en los tratados anticonversos. ${ }^{46}$ Por eso vale la pena analizarlo brevemente.

Los autores anticonversos tenían precaución y enfocaban el tema sosteniendo la pervivencia de los defectos judíos en dos argumentos:

\footnotetext{
40 Nirenberg 2014: 149.

41 Nirenberg 2008: 75.

42 Citados por Nirenberg 2014: 156 y 2000: 54.

43 Nirenberg 2014: 113 y 2008: 75-80.

44 Villanueva 1852: 259.

45 Nirenberg 2014: 158.

46 Vid. Sicroff 1969; Lea 1983: 153-181 y Caro Baroja 1961: 27-322.
} 
- No es una infección espiritual o diabólica sino física. Como el bautismo es un sacramento con poder curativo espiritual, no afecta a la naturaleza de la sangre.

- La maldad de los judíos es una cuestión de voluntad, y aunque los pecados estén perdonados, la voluntad hace que vuelvan a pecar después del bautismo.

Los defensores de los conversos sí que se refieren al poder del bautismo. Alonso Díaz de Montalvo utiliza el argumento de la purificación del bautismo para atacar a los autores del Estatuto de Pero Sarmiento. ${ }^{47}$ Fernán Pérez de Guzmán, en su biografía de Alonso de Cartagena, cree que la judaización de los conversos se debe más a la costumbres que a la maldad intrínseca del linaje judío. ${ }^{48}$ Alonso de Cartagena, en su Defensorium Unitatis Christiana ${ }^{49}$ también trata el tema:

Tanto los israelitas como los gentiles al entrar en la fe católica por la puerta del sagrado bautismo no persisten como dos pueblos o como dos linajes diferentes, sino que de los procedentes de una y otra parte se crea un nuevo pueblo. ${ }^{50}$

La multitud de hombres que vinieron de una y otra parte por la santísima ligadura del bautismo convergen en un único hombre nuevo para que de ninguna manera se reconozca el lugar de la anterior división. ${ }^{51}$

No hay que hacer diferencia alguna entre los fieles si descienden de éste o del otro pueblo, cuando todos, al estar establecidos dentro de la fe católica, constituyen un pueblo único e indivisible. De ahí que no se pueda tolerar a aquellos que llaman a unos nuevos y a otros viejos, porque no existe católico alguno que no haya llegado a la fe recientemente... ${ }^{52}$

Tanto el Concilio de Basilea ${ }^{53}$ como una bula posterior de Nicolás $V^{54}$ venían a reconocer los derechos de los conversos y su igualdad con los cristianos viejos. Relacionado con el Concilio de Basilea, Juan de Torquemada escribió un Tractatus contra madianitas ${ }^{55}$ en el que intentó proteger a los conversos:

Tanquam pessimi heretici habendi sunt qui circumcisos dicunt esse naturaliter malos, ceterum que horribilior pestis heretica esse potest quam ista, que totam fidem xpianam enervat et fedat, nam dicentes circuncisos naturaliter esse malos, consequenter habent confiteri omnes sanctos ab Abraham, cui primo data est circuncisio, usque ad Xpm. Salvatorem nostrum, qui etiam circuncisus fuit, naturaliter esse maos et, per consequens non sanctos; quo nichil assurdius vel gravius audire possunt xpiane aures. ${ }^{56}$

Per baptismum, ut testatur beatus Augustinus, et habetur De consecratione, distinccione 4 , in capitulo

47 El fuero real de España, Salamanca, 1569, f. 209v. Comentado por Sicroff 1969: 36-39.

48 Pérez de Guzmán 1986, Vida de don Pablo de Cartagena, obispo de Burgos. Madrid, BN, ms. f. 164v. Citado por Neuman 1969: 91-94. Fernández Gallardo 2002.

49 Vid. Sicroff 1969: 41-62.

50 Verdin Diaz 1992: 189. Hay edición del texto latín: Alonso (ed.). 1943

51 Ibídem: 198.

52 Ibídem: 205-6.

3 López Martínez 1954.

54 Alonso 1943: 367-370.

López Martínez y Proaño (eds.) 1957: 57.

Ibídem: 90-91. ad hoc, baptizati Christo. Incorporantur et membra eius fiant $»^{57}$

Errant in prefata dampnatissima conclusione in ea parte ubi dicunt: "quamquam sunt baptizati». Certe in hoc videntur errare in articulo fidei, de quo in simbolo Ecclesia sancta canit: confiteor unum baptisma in remissionem paccatorum. Item inquit apostolus Paulus ad Ephe. III: Unus Deus, una fides, unum baptisma; glossa: id est, equale. Item contra canones sanctissimos plures: De consecrationie, distinctione 4 in c. in Ecclesia Salvatoris, in capitulo nulli est aliquatenus ambigendum, in capitulo parvulo, in c. generant, in c. parvuli, in c. mater Ecclesia. ${ }^{58}$

El debate sobre la purificación de los judíos fue importante en el desarrollo de los estatutos de pureza de sangre en los siglos XVI y XVII, y recuperó vigor en el siglo XVIII, cuando participaron en él personajes como el inquisidor Antonio de Sotomayor ${ }^{59}$ o Juan Escobar de Corro, ${ }^{60}$ hasta llegar al Centinela contra judíos de Francisco de Torrejoncillo. ${ }^{61}$

La insinuación de Catany es de relativa importancia. Se trata de una referencia ambigua en uno de los muchos sermones que tenemos del autor. Es posible que no se predicara literalmente como la recoge el texto, que pasara desapercibida, o que recibiera alguna réplica por parte de algún otro autor o predicador.

A pesar de esta relativización, se trata de un argumento peligroso en tanto que, al mezclar el origen diabólico de la maldad judía con su pervivencia después del bautismo, ponía en duda la eficacia del sacramento. Aunque el argumento no parece haber triunfado, refleja las dudas de la argumentación cristiana en respuesta al desafío que suponía la conversión masiva de judíos al cristianismo.

\section{¿SERMONES DESTINADOS A CONVERSOS?}

La realidad de las comunidades conversas a mediados de siglo XV ha provocado un largo debate historiográfico. ${ }^{62} \mathrm{~A}$ la visión tradicional, favorecida por los documentos inquisitoriales ${ }^{63}$, que defendía que la mayoría de conversos judaizaban, se opuso la valoración de la distancia que había entre los conversos y judíos. ${ }^{64}$

Actualmente se acepta que las cosas no eran tan claras: el proceso de conversión dio lugar a una casuística muy diversa, desde conversos convencidos, conversos que intentaban

57 Ibídem: 91-92.

58 Ibídem: 97.

59 El inquisidor decía en 1632: «Tiene esta nación [los judíos] tan arraigada esta culpa [la herejía] en sus entrañas que ha habido quien diga que es una real infección y enfermedad de su sangre que se halla en todos a quien esta sangre toca, [y] que es en cierta manera para ellos los mismo que el pecado original para los demás hombres. Y si acaso alguna vez falta en alguno, a la tercera o cuarta generación torna a retoñecer y a revivir». Huerga 1994: 136.

60 El autor defendía en el Tractatus Bipartitus De Puritate que la mancha de un linaje judío era imborrable y perpetuo. Vid. Caro Baroja 1961: 304-5; Sicroff 1969: 223-236.

61 Soyer 2014: 3-46 y 75-102.

62 Ingram (ed.) 2009. Sobre el punto de vista multicultural y el interés en las relaciones culturales más que en la definición de los grupos, Gerli 2007.

63 El caso de Molina de Aragón muestra como la celebración de rituales y tradiciones judías eran vistas como herejía por la Inquisición. Zozaya 2009.

64 Netanyahu 2005. 
mantener costumbres y creencias, conversos con una religiosidad indiferente y un grupo de conversos que atacaba rituales y prácticas cristianas cuando les eran impuestas. ${ }^{65}$

En cualquier caso, los conversos formaron un grupo con identidad propia. ${ }^{66}$ Aunque la aceptación de los conversos podía variar según las zonas, en general no eran bien aceptados ni por judíos ni por cristianos, y los esfuerzos iban más encaminados a su identificación que a su adoctrinamiento. Algunos estudios sugieren una fusión de tradiciones o sincretismo fruto de la mezcla de rituales de una y otra religión, y aún el deterioro del sentimiento religioso en parte de la población conversa. ${ }^{67}$

El caso de Mallorca ofrece algún matiz a este cuadro general. Los conversos se seguían dedicando a trabajos mercantiles y artesanales. Conocemos con cierto detalle su actividad económica, pero hay poca información sobre la relación con la Inquisición, su comportamiento religioso y la aceptación de los conversos en la sociedad cristiana entre las conversiones de 1391 y 1435 y la llegada de la Inquisición real. ${ }^{68}$

Algunos gremios como los tejedores y sastres aceptaron a los conversos en sus filas, mientras otros, como los peleteros, los vetaron. ${ }^{69}$ Los conversos podían ejercer oficios como el de notario, vetado desde 1436 en Barcelona. Se creó un momento de relativa paz en que los conversos consiguieron pasar desapercibidos, y seguramente mantenían vivas tradiciones judías en el marco de la cofradía de San Miguel. Se conocen incluso matrimonios entre conversos y cristianos viejos. ${ }^{70} \mathrm{La}$ Inquisición se mostró poco activa, y los dos únicos ejecutados en esta época no consta que fueran conversos. ${ }^{71}$ La llegada de la Inquisición real endureció la persecución a los conversos, pero sin llegar a los niveles de violencia peninsular. ${ }^{72}$

Los judíos aparecen en los sermones de Bartomeu Catany como una entidad abstracta o mítica y ejemplo de todo mal, sin apenas referencias a una realidad o actividad diaria. Este tipo de visión parece ser típico de las sociedades en que no vivían judíos ${ }^{73}$ y se aleja, por ejemplo, de las referencias de los sermones a las comunidades judías del norte de Italia.

Las referencias explícitas a los conversos son excepcionales: en algunos casos, después de hablar de los judíos, aparecen referencias que pueden referirse tanto a conversos como a cristianos poco respetuosos con las normas de la Iglesia (35r., 38r., 38v., 47r.).

Las abundantes y negativas referencias a los judíos pretendían impedir el regreso de los conversos al judaísmo, al tiempo que justificaban las conversiones forzosas. Además, participaban del proceso de denigración de los conversos que apenas estaba comenzando. Los sermones de Catany son, pues, por un lado fruto de la literatura antijudía medieval y por otro lado prefiguran los ataques a los conversos, que ganarán en agresividad a finales de siglo XV y durante el siglo XVI.

\footnotetext{
65 Riera 1982.

66 Argumentos parecidos para Sicilia en Zeldes 2009: 151-155.

67 Seidenspinner-Núñez 1996: 8.

68 Santamaría 1974. Colom 1992: 43-46.

69 Riera Montserat 1973: 37. Estamos hablando de mediados de siglo XV y por lo tanto no entramos en el debate sobre los chuetas.

70 Beatriu Bertan, nieta del converso Perot Pardo casó con los caballeros Joan Palou y Macià Forteza. Clara Serra casó con el también caballero Joanot Togores.

71 Santamaría 1975: 174.

72 Santamaría 1974: 402. Ibídem 1997.

73 Un caso parecido es Dinamarca. Vid. Adams 2014.
}

\section{FUENTES REFERENTES A LOS JUDÍOS}

Los sermones cristianos utilizaron a menudo como fuente la literatura antijudía de conversos como Alfonso de Valladolid, Pablo de Santa María, Pau Cristià, Jerónimo de Santa Fe o Pedro de Caballería, y de otros no conversos como Alonso de Espina. ${ }^{74}$ Los sermones de Bartomeu Catany utilizan también algunas de estas fuentes. Un fragmento de uno de los sermones concentra las citas más importantes (28r.):

\section{La Epistola Samuelis}

La Epistola Samuelis es una carta escrita por un rabí llamado Samuel y traducida por el dominico Alfonso Buenhombre, en la que se admiten los errores imputados por el cristianismo al judaísmo. ${ }^{75}$ Aunque es probable que el texto fuera escrito por el mismo Buenhombre, se trata de un texto con mucho éxito y repercusión posterior.

La Epistola se publicó a veces junto al Scrutinium Scripturarum, ${ }^{76}$ cosa que provoca una cierta confusión. Aunque la cita aparece después de una referencia al Scrutinium Scripturarum, procede de la Epistola Samuelis, que ya era conocida en Mallorca.

Aparece manuscrita hacia 1396 en el inventario de un artesano e impresa en 1504 en poder de un ciudadano honrado. ${ }^{77}$ Guillem de Tous la copió entera en su Lumen de Lumine. ${ }^{78}$ Además, tiene una respuesta en catalán, de la que se conservan cuatro copias, y fue también traducida al castellano. ${ }^{79}$

\section{El Scrutinium Scripturarum de Pablo de Santa María}

La utilización del Scrutinium Scripturarum de Pablo de Santa María es interesante por las citas que incluye de otras obras:

\section{El hadith de la preservación}

El origen del hadith de la preservación se encuentra en Sahih Al-Bukhari ${ }^{80}$, siendo más tarde utilizado en diversos tratados de apología cristiana, entre los que destacan el Pugio fidei de Ramón Martí, la Responsio ad quendam iudaeum ex verbis evangelii Christum et eius doctrina impugnantem de Nicolás de Lira, el Sermo de conceptione Beatae Mariae Virginis y un Defensorium Beatae Mariae de Jean Vital, y un Compendium veritatis del carmelita Francesc Martí. ${ }^{81} \mathrm{~A}$ estos habría que añadir la Disputatio Abutalib (c. 1339) ${ }^{82}$ y el Scrutinium scripturarum (c. 1410), de donde procede la cita:

\footnotetext{
74 Lo consideramos no converso siguiendo los argumentos de Netanyahu 2005.

75 PL 149, col. 335-368. Vid. Biosca 2004. Limor 1996.

76 Por ejemplo, el ms. 593 de la Biblioteca Universitaria de Valencia. Vid. Riera 1989: 223. También en algunas ediciones como la de Burgos, Apud Philipum luntam, 1521, por la que cito.

77 Hillgarth 1991, II: 136, 468.

78 Barcelona, Biblioteca de Catalunya, ms. 579, f. 13r.-28r.

79 Riera 1989: 222.

80 The Translation of the Meanings of Sahih Al-Bukhari - ArabicEnglish, vol. 6, Saudi Arabia: Darussalam Publishers and Distributors, 1977: 65, hadith 4548.

81 Gay-Canton 2010.

82 Del mismo Alfonso Buenhombre, O.P., autor o traductor de la Epistola Samuelis ya comentada. García-Jalón de la Lama y Reinhardt (eds.) 2006.
} 
Catany

28ra.: Eciam in dicto Alcorano habetur: «In omnibus hominibus habuit aliquam potestatem Sathan preterquam in Eis et Mariam».

\section{Scrutinium}

In illo enim libro qui dicitur Alchoranus, in quo prophana lex Mahometica continetur, memini me legisse, quod in omnibus hominibus habuit aliquam potestatem Sathan, praeterquam in lesu et in matre eius. Ex quo constat, quod etiam apud Sarracenos beata Virgo reputari dicitur sancta. ${ }^{83}$

El hadith de la preservación fue utilizado en otros sermones además de los de Bartomeu Catany. ${ }^{84}$ En primer lugar, en un anónimo de principios de siglo Xv:

Et Mafomet in suo Alcorano: «Nullus potest evadire lagum Sathane natus de Adam nisi Jhesus et Mariam. Christus per naturam et Mariam per gratiam. ${ }^{85}$

Unos años más tarde, el obispo de Barcelona Martín García utilizaba las mismas citas:

Dios preservó a María y a Jesús de la potestat del demonio lapidado. ${ }^{86}$

Los glosadores comentan: «La virgen María fue libre de la potestad del demonio». La Sunna dice que en toda creatura nacida al mundo el demonio toma posesión, excepto en Jesús y en su madre.

Por eso dice Mahoma en la Sunna: «Todos los niños y niñas en su nacimiento los toma el demonio en posesión, excepto a María y a Jesús, a quienes no los tomó ni los pudo tomar jamás». ${ }^{87}$

El Corán y la Sunna fueron fuentes relativamente habituales no solo en la polémica interreligiosa, sino también en la argumentación sobre dogmas cristianos como la Inmaculada Concepción de María.

\section{El sefer ha-bahir o Lucidario}

El Libro de la lluminación es uno de los grandes libros de la Cábala y la exegesis judía. La datación tradicional, que lo atribuía a Nehunya ben ha-Kanah, rabino del siglo II d.C., le daba un prestigio importante. Según los editores modernos, sin embargo, el libro fue compilado en el sur de Francia a mediados de siglo XII. ${ }^{88}$ El origen remoto del libro sería una ficción literaria para dar prestigio a la obra.

El hecho que Bartomeu Catany utilice únicamente el fragmento del Lucidario citado por el Scrutinium Scripturarum indica que éste y no aquél fue la fuente del sermón:

83 Scrutinium Scripturarum 1591: 384.

84 Además de los indicados por Gay-Canton 2010: 238-9 del también franciscano Pietro Arribavene da Canneto.

85 Biblioteca de Catalunya, ms. 478, f. 12v; Catalán 2013: 165.

86 Ribera Florit 1967: 60.

87 Ibídem: 75

88 Utilizo la reedición de la traducción latina del siglo XV de Flavius Mitridades en Campanini (ed.) 2004.
Sefer ha-bahir

$$
\begin{aligned}
& \text { Scrutinium } \\
& \text { Scripturarum }
\end{aligned}
$$

Deus sanctus et benedictus iustum unum habet in seculo suo et vocatur Sadich et est ei charissimus quia sustinet mundum totum et est fundamentum eius. Et ipse nutrit et alit illum et saturat et inplet illum et germinae facit eum et crescere et letificat eum

The Book of Bahir: 201-202 omnium animarum.

Scrutinium

scripturarum: 358

\section{El Talmud}

Un único fragmento del Talmud, tan utilizado en la polémica antijudía bajomedieval, ha sido localizado en los sermones de Catany (33v.). No es posible afinar si procede de una obra de polémica o lo conocía directamente el autor.

\section{BARTOMEU CATANY Y LA APOLOGÉTICA ANTIJUDÍA}

La literatura antijudía creó un estereotipo que convirtió a los judíos en un chivo expiatorio de los males de la sociedad bajomedieval, hasta justificar la conversión forzosa y la expulsión de los judíos de diversos territorios cristianos. ${ }^{89}$

Estos últimos años se han multiplicado los estudios sobre exegesis y predicación franciscana y su relación con la literatura hebrea y la polémica antijudía ${ }^{90}$, así como sobre la relación entre órdenes mendicantes y judíos en el área mediterránea ${ }^{91}$, estudiando tanto casos concretos ${ }^{92}$ como la predicación hacia los judíos en general. ${ }^{93}$

A pesar de que se había defendido una cierta división entre una escuela dominica más orientada a la predicación y una escuela franciscana más centrada en la exegesis ${ }^{94}$, el interés de los franciscanos en la predicación a judíos y conversos y el uso que hacen de fuentes hebreas y de literatura antijudía es muy destacable. Entre los franciscanos (muchos de ellos observantes como Catany) que predicaron a judíos o que utilizaron fuentes hebreas en sus tratados ${ }^{95}$ encontramos a Ponç Carbonell ${ }^{96}$ (1260-1337), Nicolás de Lira

89 Losada 2013; Edwards 1984.

90 Roest 2014; Copeland Klepper 2000 y Fidora 2013.

91 Myers y MacMichael (eds.) 2004; Debby 2014.

92 Ben-Aryeh 2001: 179-188; Luzzati y Galasso 1996. Sobre Bernardino de Siena, véase Mormando 1999.

93 Cohen 1982. Abulafia (ed.) 2002. Para la península ibérica, véase Orfali 2012.

94 Copeland 2000.

95 Para los predicadores italianos véase Hughes 1986.

96 Fidora 2013. 
(1270-1349) ${ }^{97}$, Bernardino de Siena ${ }^{98}$ (1380-1444), Giovanni da Capistrano ${ }^{99}$ (1386-1456), Bernardino da Feltre ${ }^{100}$ (14391494), Bernardino da Bustis (1450-1513) y Alfonso de Espina († 1496).

Los sermones de Catany apenas transmiten los argumentos y discusiones teológicas de polémica entre judaísmo y cristianismo. Catany se limita a transmitir una imagen negativa de los judíos sin demasiada elaboración ni argumentación, utilizando un lenguaje más expositivo que argumentativo.

A pesar de la influencia de sus compañeros sicilianos como Mateo de Agrigento y Giovanni de Pistoia en el desarrollo de la observancia en la Corona de Aragón ${ }^{101}$, los sermones muestran más influencia de los franciscanos castellanos que de los italianos.

Los sermones italianos atacaban en general la usura y las actividades diarias de los judíos, y no ofrecen muchas referencias a época evangélica ni a conceptos como la impureza de sangre. ${ }^{102}$ Tampoco aparecen en Catany insultos explícitos como los de un Dominici. Más cercanos parecen los sermones de Catany a la polémica antijudía y anticonversa castellana. Como hemos visto, hay influencia directa del Scrutinium Scripturarum de Pablo de Santa María y del Fortalitium fidei de Alonso de Espina.

También hay semejanzas con la Sentencia de Pedro Sarmiento, que representa un precedente de pureza de sangre, según el cual los conversos tienen una tendencia a la judaización, aún sin estar determinados por su linaje. ${ }^{103}$

Los sermones de Bartomeu Catany tampoco muestran semejanzas significativas con los sermones de su compatriota Ramon Llull, que prefería un tono más argumentativo y menos insultante que el que aparece en Catany y en general en la apología cristiana. ${ }^{104}$

Finalmente, tampoco la comparación con los sermones de Vicente Ferrer da grandes semejanzas. Seguramente por haber sido transcritos en latín, la versión que nos ha llegado de los sermones de Catany carece de los exempla, el humor y la vivacidad típica de los sermones catalanes de Vicente Ferrer. Además, los sermones de Catany no intentan segregar a comunidades concretas o reales, sino desprestigiar al judaísmo, por lo que los ataques son más genéricos que los de Ferrer.

Pocos años después, la Requesta que presentaron Bartomeu Caldentey, Francesc Prat y Joan Domènech al gobernador de Mallorca para impedir la actividad profesional del médico judío Isaac utiliza un lenguaje mucho más agresivo que el de Catany, mostrando así una tendencia clara en la escalada retórica antijudía de la que los sermones de Bartomeu Catany sin duda participan. ${ }^{105}$

\section{Copeland 2000 .}

98 El antisemitismo de Bernardino de Siena ha sido puesto a prueba per Mormando 1999: 164-218.

99 Sedda 2014.

100 Muzzarelli 2014.

101 Mateo de Agrigento visitó Mallorca en mayo 1428. Rubió 1990: 57 solo dice que estuvo unos días en Mallorca. Sanahuja 1959: 927-928, asegura que predicó.

102 Sobre el tema de la usura en Bernadino de Siena, Mormando 1999: 182-191.

103 Vidal 2013: 226-7.

104 La fluctuante posición de Ramon Llull ante los judíos ha dado para bastante literatura, pero queda fuera de este estudio. Para profundizar, vid. Hames 1998, con bibliografía abundante.

105 Vid. Supra, nota 20.

\section{EL PAPEL DE LOS SERMONES EN LA PERSECUCIÓN RELIGIOSA}

Baer señalaba que «el odio hacia el pueblo judío no presentaba en Aragón, en la segunda mitad del siglo xIV, la forma grosera y simple que exhibía en Castilla. No había entonces en Aragón una literatura que pudiera servir de órgano de difusión para este odio ${ }^{106}$. Al hablar de los ataques de 1391, sin embargo, el mismo autor admite que el trato había cambiado. La reina Violante intentaba impedir debates públicos con los judíos por miedo que:

Per lo acabament del dit procés se pogés seguir gran escàndol en la aljama nostra dels juheus de Barachinona, si en la dita ciutat se acabava, per tal com lo poble, qui tals ha en gran oy, los hauria en molt maior. ${ }^{107}$

El papel de la predicación en la escalada de odio y violencia es innegable. Los sermones de Bartomeu Catany dan testimonio de las acusaciones hechas a los judíos desde el púlpito y de su papel de intermediario o transmisor entre las acusaciones formuladas por las élites intelectuales y la población, sembrando la semilla del odio a judíos y conversos.

La imagen negativa de los judíos pretendía justificar la conversión de los judíos y convencer a los conversos de la maldad de su antigua religión. Además, la tradicional imagen negativa del judío estaba cambiando de significado. Estaba pasando de representar a una religión a representar a un linaje. Ya no iba dirigida a los judíos, sino a los conversos, que iban a heredar los tópicos e insultos que se habían fabricado siglos atrás para los judíos.

El odio es un fenómeno cultural que se aprende. Los sermones de Catany ofrecen los argumentos básicos del antijudaísmo:

- Acusaciones de maldad, obstinación y ceguera.

-Degradación de la persona, animalización y demonización.

- Victimización de la mayoría y legitimación de la violencia en supuestos ataques previos por parte de la minoría.

Si los argumentos de Catany fueron habituales o un extremo radical en la predicación medieval en catalán no se puede asegurar dada la poca cantidad de sermones catalanes conservados y editados. ${ }^{108}$ Las noticias que tenemos indican que la agresividad antijudía se mantenía en un nivel muy elevado al menos desde principios de siglo XV. ${ }^{109}$

Los sermones de Bartomeu Catany ilustran una época fundamental en la evolución de las relaciones entre cristianismo y judaísmo y sitúan a su autor entre los más destacados predicadores en el contexto cristianismo medieval. Solo por ello, merecen la atención que hasta ahora se les ha negado.

106 Baer 1981: 371.

107 Ibídem: 404

108 Más allá de los de Vicente Ferrer, por supuesto. Un sermón antijudío anónimo de principios de siglo xV en Catalán 2013: 145-146 y 433. 109 Cátedra 1994. 


\section{APÉNDICE}

\section{Fragmentos de sermones citados en el artículo}

2r.: Tamen si diligenter attendimus ad vicia que nostrum impediunt intellectum ne dum nostrum agnoscamus. Certe inter cetera est malicia. Unde malicia est velamen impediens intellectum ne quod rectum est discernat. Hanc maliciam iudey contra Christum habuerunt, quibus dicit hodie lohannes in evangelio: "Medius vestrum stetit quam nescitis ${ }^{1}$ », lohanis primo originaliter et in evangelio hodierno. Ecce quod malicia excecavit vestros intellectos 0 , iudey, et quia pertinaces estis "Medius vestrum stetit quem nescitis ${ }^{1}$ ", lohanis primo, originaliter et in evangelio hodierno. Ecce quod malicia excecavit vestros intellectos o, iudey, et quia pertinaces estis, medius vestrum stetit quam nescitis (...)

Et licet Deus aliter potuisset redimere genus humanum et si fecisset bene fecisset. Hoc tamen ei placuit et fuit convenientissimum ut ei teneamur tamquam creatori et redemptori. Licet iudey hoc nesciant quia erant contumaces. Unde "Contumacia est auctoritati maioris et contemptu non obedire sed obviare ${ }^{2}$ » de quibus dicitur leremie IIo: «Patres vestri elongaverunt a $\mathrm{me}^{3} »$, «Tenentes legem nescierunt $m^{4}$ », et vos similes eis estis quia "Medius vestrum stetit quem nescitis», que fuere verba thematis...

${ }^{1}$ lo. 1 , 26. $\mid{ }^{2}$ Comentarii sancti Bernardini Senensis in Apocalypsim, en Sancti Bernardini senensis ordinis seraphici minoris sermones eximi de Christo Domino, Venecia, 1745, p. 92. | ${ }^{3}$ Ier. 2, 5. | ${ }^{4}$ Ier 2, 28.

5r: [Antichristus] Erit maximus peccator, omni malicia plenus principale dyaboli membrorum et capud malorum homini et dux sub principe dyabolo. Unde glosa $2 \underline{a}$ ad Thessalonicenses ॥lo: "Sicud in Christo omnis plenitudo divinitatis habuit, ita in antichristi omnis plenitudo iniquitatis. Erit enim mendax, blasfemus, luxuriosus, ultra modum ypocrita et simulabit sanctitatem, et hoc ut facilius et caucius possit decipere quoscumque. Ideo veniet in Iherusalem et circuncidetur et plebs iudayca adherebit et credens ipsum esse Christum ei promissum ${ }^{1}$. Unde Aymo. 2a Thessalonicenses 20: "Confluent ad eum omnis iudey et reedificabunt templum a romanis destructum et ibi sedebit dicens se esse Deum»².

${ }^{1}$ Haimo de Auxerre, Expositio in Apocalipsim 2, 7. PL 117, 780B Hugue Ripellin, Compendium theologicae veritatis, Ulm: Johannes Zainer, 1481. lib. 7, cap. 6; Cf. Alfonso de Espina, Fortalitium fidei, 1471: 145v. | ${ }^{2}$ Haimo de Auxerre, Expositio in Apocalipsim, cap. 2. PL $117,780 B$.

6r.: Unde iudey videntes lohanis asperitatem in vestibus parcitatem in cibus et potibus et scientes ipsum esse filium sumum sacerdotis, non intelligentes scripturas, putaverunt ipsum esse Messyam eis promissum, magis quam Christum, eo quo Christus utetur vestibus comunibus tamen pauperibus, manducabat cum peccatoribus panem et vinum et erat filius cuiusdam pauperis mulieris. Eciam aliqui monebantur ex invidia contra Christum.

9r.: 3us modus [detraccionis] est bona occulta negare ut faciebant iudey contra Christum. De ceco per eum illuminato, lohannes $\mathrm{X}$, et hoc ne a populo diligeretur et ne populus ad eius doctrina converteretur. 23vb.: Sed tamen fuit talis et tanta insania et tam magna malicia homini quo non solum nuncios a Deo missos non receperunt sed et illos persecuti sunt et diversis penis occiderunt propter eorum duriciam cordis, maliciam et infidelitatem. Unde leremia VIIo: «Misi ad vos omnes servos meos prophetas per diem consurgens diluculo clare et manifeste et mittens et non audierunt me nec inclinaverunt aurem suam ${ }^{1} »$, sed induraverunt cervicem suam, et "Abierunt in voluptatibus ${ }^{\text {a }}$ suis et pravitate cordis sui mali et penis operati sunt quam patres eorum ${ }^{2}$ », in Egipto "Periit enim fides et ablata est de ore eorum ${ }^{3} »$. Glossa: Non possunt iudey se excusare quod non habuerunt admonitores in umbra tempore prophetarum. "In tempore Christi plene conpletum est, cuius disciplinam noluerunt audire. Ideo ${ }^{b}$ eleganter infertur: periit fides [et ablata est] ${ }^{4} »$, tanta fuit eorum superbia et cordis duricia. Non ergo non solum non audierunt, sed persecuti sunt, et occiderunt diversos modis et penis. Ideo dicit Christus ut ostendat quod obdurati sunt: "Lapidas eos qui ad te missi sunt ${ }^{5}$ ", Mathei XXIIIo capitulo originaliter recitative in evangelio hodierne festivitatis (...).

Ysaia XLII: "Quis cecus misi servus meus et surdus nisi ad quem nuncios meos missi ${ }^{6}$ ", et conversi sunt retrorsum, scilicet, a me et apostolos repellendo, quia predicantibus apostolis credere noluerunt. Hic arguntur clerici de cecitate qui apti nati sunt videre Deum in scripturis et nolunt videre. Et layci de surditate qui aperta habunt aures ad adulaciones et detracciones, non autem ad sermones et clausas ad Deum moniciones sicut superbe et pharisey et populi iuderum. Unde leronimus: Missit «Quosdam prophetas qui ventura predicent, alios sapientes qui noverunt quando debeant proferre sermonem, alios scrybas in lege doctissimos, et presecuti sunt eos. Ex quibus |24ra. lapidatus est Stephanus ${ }^{7} »$. Merito conqueritur Christo de Iherusalem quia habitantes in ea obstinati sunt: "Lapidas eos qui ad te missi sunt», que fuere verba thematis.

${ }^{1}$ ler. 7, 25. | ${ }^{2}$ ler. 7, 24-5. | ${ }^{3}$ ler. 7, 28. | ${ }^{4}$ Glossa ordinaria, leremiae, Caput VII, vers. 28, PL 114, col. 21. | ${ }^{5}$ Mt. 23, 37. | ${ }^{6}$ Is. 42, 19. $\mid{ }^{7}$ leronimus, Commentarium in Matheum. PL 26, 15-218.

a Vulg., Voluntatibus. | ${ }^{\mathrm{b}}$ Glossa, unde.

24r.: clarum est quod iudey semper persecuti sunt viros sanctos et eos occiderent. Unde dicitur hodie in evangelio: "Ecce ego mitto ad vos prophetas et sapientes et scribas et ex illis occidetis et crucifigetis et ex eis flagellabitis in synagogis vestris et persequimini de civitate in civitatem ut veniat super vos omnis sanguis iustus qui effusus est super terram ${ }^{1}$ ». Glosa: "Occidistis eos qui annunciaverunt Christum venturum», scilicet, serra lignea. leremiam lapitantes, Zachariam inter templum et altare, et eos occidetis qui annunciant Christum venisse, ut Paulum crucifigetis, ut Petrum et lacobus, sapientes qui scripturas exponunt, "Scribas latores morum», "Ut veniat super vos debita ultio pro effusione sanguis iustorum quos iniuste persecuti» ${ }^{2}$ estis, quod est maleficium punitivum.

${ }^{1} \mathrm{Mt} .23,34 . \mid{ }^{2}$ Anselmus Ladinomensis, In evangelium Matthaei, PL 162, 1447.

26ra.: Istis modis circuncidi debemus non corporaliter sicud iudey qui iam non dicuntur circundidi, mas retallats, quia ultimus circumcisus fuit Christus qui finem illi legi dedit. 
28ra: De isto puero hodie a regibus adorato et de eius perfeccione et eciam sue matris et sui patris condicionibus. Unde de Christo et eius patre et matre in Alcorano quod dicitur de familia Domar et recitatur a magistro Paulo de Sancta Maria episcopo Burgensis in libro Scrutinii Scripturarum. 'Eyce' est verbum Dei qui habuit omnem sapienciam et scienciam, et "scivit secreta cordium ${ }^{1}$ » et "habuit a Deo potestatem faciendi miracula et sanandi omnem languorem et mortuos suscitandi² $»$, Matheo ultimo: «Data est mihi omnis potestas ${ }^{3} »$. De Maria in eodem capitulo: «Dixit angelus ad Mariam: "O Maria, Deus prelegit te super omnes mulieres omnium seculorum et posuit te quasi unum medium dividens inter homines terrenos et angelos Dei in paradiso deliciarum ${ }^{4 \prime \prime}$ ». Hec sunt verba magristri Samuelis de Marrracus in quodam libro quem fecit de Christo et misit illum ad Raby Ysach synagoge eiusdem regnum. Eciam in dicto Alcorano habetur: "In omnibus hominibus habuit aliquem potestatem Sathan preter quam in Eyce [id est, Ihesum] et Mariam ${ }^{5}$ ». Et hec verba dicit Magister Paulus. Alia vero magister Samuel. Unde lob VIII을 «Interoga generacionem pristinam et diligenter investiga patrum memoriam ${ }^{6}$ », scilicet, secundae scola, "Hesterni enim sumo et ignoramus, [quoniam sicut umbra dies nostra sunt super terram et] ipsi docebunt te et loquentur tibi et de corde suo proferent eloquia ${ }^{6} »$. Hec sunt verba que dicunt infideles fidelibus ut scilicet interrogent doctores et prophetas antiquos|28rb. secunde scole. Ideo secunda scola est iudayca, quod est sinagoga Moysi. Hic dicemus secundum magistros talmudistas.

"Unde Daniel IIo: «Ipse revelat profunda et abscondita et novit in tenebris constituta el lux cum eo est ${ }^{7}$ ». Super hoc rabbi Alba: «Hec lux regis Messie» est de qua in Psalmos: «In lumine tuo vedebimus lumen ${ }^{8} \rrbracket$. Ecce ergo quod Messias est lux divina et per consequens Deus". Eciam "Proverbiorum $\mathrm{X}$ :: «lustus autem est fundamentum sempiternum ${ }^{10}$ ». Super hoc rabbi Nehunia in Lucidario: «Deus sanctus et benedictus habet quandam iustum qui est sibi valde dilectus, eo quod sustinet mundum et gubernat et facit germinare, et ipse est fundamentum omnium animarum efective et meritoria ${ }^{11}{ }^{1}{ }^{12}$,, de quo iusto dicitur in Psalmis CXVIIo: «Benedictus qui venit in nomine Dominum Deus», Dominus et deluxit nobis rabbi lohanam: "Usquequo laborabimus in redempcionibus et subieccionibus a modo non querimus illuminari nisi per ipsum Deum in sua persona et tunc dicemus: [Benedictus qui venit in nomine Domini,] Deus dominus ${ }^{13}$ ».

\footnotetext{
${ }^{1}$ Epistola Samuelis, PL 149, 366. $\mid{ }^{2}$ Epistola Samuelis, PL 149, 366; Corán, sura 3, 48-9. | ${ }^{3}$ Mt. 28, 18. | ${ }^{4}$ Epistola Samuelis, PL 149, col. 366. Cf. Corán, sura $3,42 . \mid{ }^{5}$ Scrutinium scripturarum, ed. 1591: 384. | ${ }^{6}$ Iob. 8, 8-10. $\mid{ }^{7}$ Dan. 2, $22 \mid{ }^{8}$. Ps. 35, 10. | ${ }^{9}$ Scrutinium Scripturarum: 357. I ${ }^{10}$ Prov. 10, 25. | ${ }^{11}$ The Book of Bahir: 201-202; Scrutinium scripturarum: 358. ${ }^{12}$ Scrutinium Scripturarum: 358. | ${ }^{13}$ Scrutinium Scripturarum: 356-357.
}

33v.: Unde talmudiste maxime, Rabbi Samuel in libro qui dicitur Canedrini in capitulo Helec exponit de vocacione ultima fienda per Messyam in qua pauci iusti iudeorum vocabuntur sicud quando egressi sunt de terra Egipti quia de sexcentis milibus non intraverunt in terram promissionis nisi Caleb et losue quia Christus non vocavit nisi iustos ${ }^{1}$.

${ }^{1}$ The Babylonian Talmud, vol. III: Seder Nezikin. Londres: The Soncino Press, 1935. cap. 111a, p. 762. 35rb: multi messuerunt spinas, scilicet, errores aberrantibus seminatos, qui tam hereditatem religionis Christiane acceperant, id est, in baptismo, et tamen eis non prodeat.

38rb: septem que sunt in iudeis mala, id est, contumacia contra Deum, indignacio contra Christum, doctrina falsa contra evangelium, blasfemia contra virgine, invidia contra ecclesiam, avaricia contra christianum. Que recte sunt omnia in iudeis et ecclesia quibusdam malis christianis. Ideo sunt novissima peiora prioribus.

39ra.: Christus iam hodie totaliter derelinquit et repulit luda| ${ }^{39 r b}$ ycam synagogam et congregacionem et extra illam exivit tamen quod huc intrabit die Dominica ut rex duo eidem faciendo:

Primo expoliando eam.

20 captivando.

Expoliavit autem eam dominio sacerdocio sacrificio causa quia ipsi iudey totaliter Deum derelinquerunt et in omnibus operibus post posuerunt. Unde Ezequielis 39: Hec dicit Dominus: «Eo quod relinquerint me [et] absconderim faciem meam ab eis ${ }^{1}$ ». «Et ponam gloriam meam in gentibus et videbunt gentes iudicium meum quod fecerim ${ }^{2} »$. Gentes sunt gentiles, id est, nos et videmus iudeos inter nos iam expoliatos dominio sacerdocio et cerimoniis, eo quia derelinquerunt Deum. Ideo ab eis se ascondit subtrahendo suam graciam.

2o captivavit illam. Nam iudey dispersi sunt per universum mundum inter gentes tanquam captivi, in qua captivitate erunt perpetue, Daniel IXo et Amos IIㅇ. Unde Neeme IXo: "Induraverunt cervices suas et noluerunt audire ${ }^{3}$ », "Recesserunt a te et proiecerunt legem tuam post terga sua ${ }^{4}$ » et "Fecerunt blasfemias grandes ${ }^{5}$ » in conspectu tuo. Ideo "Dereliquisti eos in manu inimicorum suorum et possederunt $\operatorname{eos}^{6} »$, id est, tamquam captivos. Ita quod omnia hec fecerunt iudei contra Christum. Dominus eis in templo predicaret et corrigeret propter que omnia "Abscondit se et exivit de templo», lohannis VIIIo originaliter in evangelio hodierno. Ecce quod Christus propter iudeorum obstinacionem blasfemias et vituperia synagogam reliquid. Postquam ergo extra synagogam exivit ad gentes se transtulit. (...)

Quia iudey videbant Christum abstinere se ab operibus eorum tamquam ab inmundiciis et in facie dicebat eorum maleficia declarando veritatem divinorum secretorum Dei aderat illum in tantum quod nolebant eum videre super terram. Ideo continue cogitabant quomodo possent eum interficere. Sapiencie IIo: Venite, «Dixerunt impii non recte cogitantes», "Opprimamus virum [pauperem] iustum ${ }^{7}$ ». Iniuste "Quia contrarius est nobis ${ }^{8}$ ", "Abstinet enim se aviis nostris tamquam ab inmundiciis ${ }^{9}$ », "Et filium Dei se nominat ${ }^{10} »$, morte turpissima condempnemus eum. Nam Christus verba que dicebat operibus roborabat faciendo miracula. Ideo iudey duo faciebant:

Primo expernebant eius doctrinam.

2ㅇ eius opera demonio atribuebant.

Primo ergo iudey doctrina asperbebant ne a populo bona videretur et agnosceretur. Unde lob XXIㅇ: «Dixerunt Deo recede a nobis ${ }^{a}$ scienciam viarum tuarum, nolumus quis est omnipotens ut serviamus ei et quid nobis proderit 
si oraverimus eum ${ }^{11} »$. Ecce quod Christi doctrinam nolebant sed spernebant ac si Deum non haberent. Et ideo ut eorum dicta populis confirmarent sequitur.

$2 \mathrm{~m}$, id est, quod opera Christi dyabolo ${ }^{\mathrm{b}}$ atribuebant. Causa est ut populum a Christi devocione averterent et contra eum insultarent et comoverent, quod est sedicio et avalot. Unde leremie Vo: «Negaverunt Dominum et dixerunt Non est ipse Dominus ${ }^{11}$ », "Populo autem huic factum est cor incredulum et exasperans recesserunt et abierunt et non dixerunt in corde suo: metuamus Dominum Deum ${ }^{12}$ » sed pocius recede a nobis. Unde Psalmos IIo: «Principes convenerunt in unum adversus Dominum et adversus Christum eius ${ }^{13}$ » concordes in malicia. Videns ergo Christianus experimentaliter quod iudey suam docrinam spernebant et quod demonio sua opera atribuebant moti invidia, malicia, avaricia et sic de quolibet vicio. Nam iam erant contumaceus. Ait id Deuteronomium XXXIIo: «Generacio enim perversa est et infidelis filii ${ }^{14}$ ». Ideo "Abscanam faciem mean ab eis et considerabo novissima eorum ${ }^{15}$ " et quia reprobati sunt solum restat novissimum, id est, | ${ }^{39 v a}$ dampnacio. Ideo "Abscondit se et exivit de templo», que fuere verba thematis.

${ }^{1}$ Ez. 39, 23. $\mid{ }^{2}$ Ez. 39, 21. $\mid{ }^{3}$ Nee. 9, 29. | ${ }^{4}$ Nee. 9, 26. | ${ }^{5}$ Nee. 9, 18. $\mid{ }^{6}$ Nee. 9, 28. $\mid{ }^{7}$ Cf. Sap 2, 10. $\left.\right|^{8}$ Cf. Sap 2, $12 . \mid{ }^{9}$ Sap. 2, 16. $\left.\right|^{10}$ Sap. 2, 13. $\left.\right|^{11}$ ler. 5, 12.| ${ }^{12}$ ler. 5, 23-24. | ${ }^{13}$ Ps. 2, 2. | ${ }^{14}$ Deut. 32, 20. | ${ }^{15}$ Deut. 32, 20.

${ }^{\mathrm{a}}$ Sigue sciarum, error de escritura, tachado. | ${ }^{\mathrm{b}}$ Sigue atribue, error de escritura, tachado.

40r.: tulerunt lapides ut iacerent in eum, quod est crimen lese maiestatis.

45vb.: $2 \mathrm{~m}$ est detraccio inferna, scilicet, iudeorum Christo detrahendum. Unde: "Admirate sunt turbe»" populares credentes, sed sacerdotes signum de celo querebant ac si ista quatuor opera possent firi virtute creata. Sed pharisey dicebant: «In Belzebuc principe demoniorum eicit demonia» $»^{2}$. Et ecce blasfemia in Spiritum Sanctum. Nam quod Dei est atribuebant demonium. Sed Christus per raciones necessarias probat ipsos mentiti.

${ }^{1}$ LC. $11,14 .\left.\right|^{2}$ LC. $11,15$.

47ra: abscondit Christum a iudeis et a cunctis pravis hominibus est sciendum quod pravitas est perversitas

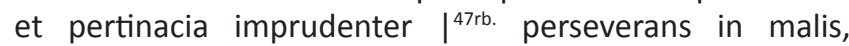
convertens bonum in malum ut iudey fecerunt et adhuc faciunt et eciam perversi christiani (...) Hec triplicata pravitas erat in iudeis et est hodie in pravis christianis.

(...)

2a pravitas oris malicie est iniquitatis corda eorum exequantis, videntes mirabilia noluerunt credere sicud nec modo mali christiani infecti et venenati malicia. Et ab istis abscondit suam clemenciam, nec vivat in tribulacionibus.

47ra.: Ex pravitate enim peccator temerarie insurgit contra Deum quasi eius verba et precepta inpugnando et ei pro posse obiciendo ut iudey. Et sic fuerunt omnio deserti a Deo. Nam propter iudeorum pravitatem hodie Ozee IIIㅇ: "Sedebunt filii Israel sine rege et sine rincipe et sine sacrificio et sine altari» ${ }^{1}$. Christus hodie exivit eorum synagogam et duo ei intulit: primo eam privavit dominio sacerdocio et per consequens sacrificio.

20 captivavit eam, de qua captivitate nunquam exibit. Eo quia iudey propter eorum duriciam cordis et pravitatem Christo obedire noluerunt.

(...) Cum ergo ita sit quod pravitas abscondit Christum a iudeis et a cunctis pravis hominibus est sciendum quod pravitas est perversitas et pertinacia imprudenter $\left.\right|^{47 \mathrm{rb} .}$ perseverans in malis, convertens bonum in malum, ut iudey fecerunt et adhuc faciunt et eciam perversi christiani et tale pravitas est triplex:

Primo pravitas cordis ex superbia. Et istis abscondit Christus suam potenciam.

2o pravitas oris ex malicia. Et istis abscondit Christus suam clemenciam.

30 pravitas operis ex avaricia et dolositate. Et istis abscondit Christus suam noticiam.

Hec triplicata pravitas erat in iudeis et est hodie in pravis christianis. Nam iudei propter eorum superbia et infidelitatem noluerunt credere verbis Christi. Ymmo nec signis evidentibus, ut de ceco nato vel pocius atribuebant dyabolo. Unde Deuteronomio XXXIIo: "Generacio prava atque perversa $»^{2}$, «Et infideles filii abscondam faciem meam $a b$ eis et considerabo novissima eorum faciem ${ }^{3}$, id est, potenciam ostendendo me passibilem norte quoniam hodie tractant, et eis dabo in futuro novissimam mortem. leremie XIIIo: "Conputrescere», id est, ut stercora conculcabo «faciam superbiam luda et Iherusalem et populum istum pessimum qui nolunt audire verba mea et ambulant in pravitate cordis sui mali» ${ }^{4}$, «In abscondito plorabit anima a facie superbie $»^{5}(\ldots)$.

Pravitas est triplex, scilicet:

Primo cordis.

2o oris.

3o operis.

Et ab omnibus abscondit se Christus.

Primo est pravitas cordis, ut cum quis semper contra proximum excogitat ac parat malum ingenio se et fraudulenter, ut faciebant iudei contra Christum. Unde Gregorius XXIo: «Mora mens prava semper in laboribus est, quia aut molitur mala que inferat vel metuit ne hec sibi ab aliis inferantur. Et quidquid contra proximos excogitat, hoc contra se cogitari a proximis formidat $»^{6}$. (...)

2a pravitas et oris, et hoc est in perverse intelligendo et exponendo veram doctrinam Christi, ut iudey et heretici fecerunt et faciunt. (...)

Tercio est pravitas operis, et hoc est in oppressione et violencia populurom et iustorum ut faciebant iudey contra Christum et perversione iudicii.

${ }^{1}$ Os. 3, 4. $\mid{ }^{2}$ Deut. 32, 5. $\mid{ }^{3}$ Deut. 5, 20. $\mid{ }^{4}$ Ier. 13, 10. $\mid{ }^{5}$ ler. 13, 17. | ${ }^{6}$ San Gregorio, Moralia in lob, liber 12, cap. 39.

47v.: Nam iudey noluerunt recipere doctrinam Christi nec disciplinam nec obedienciam et propter hoc eorum pravitatem. Ymmo oderant Christum propter duo:

Primo propter eius vite sanctitatem.

2o propter eius doctrina veritatem.

Sanctitatem Christi excitabantur ad invidiam et veritate ad iracundiam. Et quia isti erant viciosi Christus ab eis se abscondit et synagogam exhereditavit. Ab istis ergo viciis et 
viciosis debemus nos separare et abscondere cum Christo sequendo eius vitam doctrinam et veritatem.

(...)

Ideo separacio a talibus est virtuosa et nobis necessaria si cupimus esse de numero et societate sanctorum.

48r.: Sinagoga est habitacio ruinosa. Nam causa destructiva cuiuslibet comunitatis est contemptus verborum Dei et legis, et quia iudey contempnebant doctrinam Christi veram et non receperunt eam. Ideo Christus exivit ab eis et insiderunt in omne malum. Unde Gregorius «In hoc datur intelligi quod ab illis exit et absconditur qui eius verba veritatis sequi contempnunt $»^{1}$.

${ }^{1}$ Cf. Thomae Aquinensis, Super evangelium s. loanem lectura, Ed Rafael Cai (6a ed.: Marietti, Taurini-Romae, 1972), cap. 8 lectio. 8.

48v.: Et iudey sunt dure cervicis non credent.

49v.: «Hec cogitaverunt et erraverunt. Excecavit illos malicia eorum et nescierunt sacramenta Dei ${ }^{1} »$. Causa defective huius congregacionis fuit invidia sanctitatis Christi et malicia contra eius opera virtuosa et verba salutifera contra eorum crimina ut apparet in littera auctoritatis allegate de quibus dicitur Luce XXIIo: «Hec est hora vestra et potestas tenebrarum ${ }^{2}$ » quia malicia vestra vos excecavit. Ideo habet puritatem in vobis. Ideo dicunt in hac congragacione Christus pereat quia venit hora ut transeat.

${ }^{1}$ Sap. 2, 21-22. ${ }^{2}$ Lc. 22, 53.

55ra.: Et sic homo infirmatur ad bonum et fit proclivis ad malum, quia intellectus cecatur et iudicat malum bonum et illo ordine voluntas amat. Et ideo accenditur malicia ut bonum inpungnet. Et tales fuerunt $\left.\right|^{55 r b}$. iudey quorum tanta fuit malicia et inniquitas in cordibus eorum et est hodie quod nichil locuti sunt ne continue locuntur nisi in detrimentum, iniuriam et oprobrium ${ }^{\text {a }}$ et infamiam Christi Ihesu. Unde psalmos XXVIo: "Insurrexerunt in me testes iniqui en mentita est iniquitas sibi ${ }^{1} »$. Nam ea que de me dicebant falsa erant. Ymmo totaliter inpossibilia. Ideo tamquam obstinati loquebantur ete incorrigibiles dicentes eum seductorem et Dei blasfematorem et divinatis usurpatorem et nunc incantatorem dicentes: "Demones habes ${ }^{2}$ », Iohannis VIII capitulo originaliter et in evangelio hodierno. Quia tu dicis alta et subtilia que nos non intelligimus, dicis secreta cordium, concludimus dicentes quod demonium habes. O mira, O incogitabilis clemencia et paciencia salvatoris. Venerat homines liberare a potestate dyaboli et tamen ei inponunt iudey rabidi quod benedicunt ipsi, "Demonium habes», hoc enim inproperando dicebant et quasi volentes eum confundere. Unde Psalmo LXXIII: "Usquequo Deus inproperabit inimicus inritat adversarius nomen tuum in finem ${ }^{3}$ " provocando ad eorum malum finaliter. Nos vero qui catholici sumus ab hoc crimine liberi sumus. Non enim decet Dei maiestatem blasfemare. Unde Levitici XVIIo: "Nequaquam inmolabunt hostias suas demonibus ${ }^{4}$ ». Sed oraciones tibi Deo recurrendo ad sacratissimam Virginem tamquam ad adiutorium omnium necessitatum dicendo: Ave Maria...

Si diligenter attendere volumus ad quorumumque peccatorum despectum et captivitatem. Unde eis tanta et talia mala proveniunt maxime perfidis, scilicet iudeis et aliis dicetur quod contumacia est causa. Unde «Contumacia est auctoritati maioris ex contemptu obviare ${ }^{5}$ ", sicut iudey, qui Christo viventi in carne in omnibus eius operibus obviarunt et adhuc faciunt continue. Unde propter istam contumaciam sex opera crudelia exercent continue contra Christum et eius ordinaciones:

Primum opus est indignacio contra personam Christi quam summe habunt exosam, et de illa non possunt loqui nisi malum.

$2 \mathrm{~m}$. opus est, scilicet, iudeorum et hereticorum falsa doctrina contra evangelium.

$3 \mathrm{~m}$. opus supradictorum est blasfemia contra beatissimam Virginem, continue vituperando eam.

$4 \mathrm{~m}$. opus est invidia contra ecclesiam, semper dolendo de eius prosperitate et gaudendo de eius adversitate.

$5 \mathrm{~m}$. opus iuderorum est avaricia contra christianum ut per quodcumque modum sive usurarium vel alia christianos destruant.

$6 \mathrm{~m}$. opus iudeorum est impudicicia contra seipsos. Sunt enim inpudicissimi et fex et dorsum tocius mundi. Et quia videbant Christum eorum inpudiciciam corrigentem et elongacionem a Deo totalem, inproperabant Christum. Unde Origenes: «Quia iudey viciis pleni erant nec a Christo corrigi volebant ${ }^{6} »$. Ymmo tunc deteriores fiebant. Ideo tamquam contumaces dicebant "Demonium habes», que fuere verba thematis.

${ }^{1}$ Ps. 26, 12. $\left.\right|^{2}$ lo. 8, 48. | ${ }^{3}$ Ps. $73,10 . \mid{ }^{4}$ Lev. $17,9 . \mid{ }^{5}$ Sancti Bernardini Senensis, Comentarii in Apocalipsim, en Sancti Bernardini Senensis Ordinis Seraphici Minorum Sermones eximii de Christo Domino, augustissimo Eucharistiae Sacramento deipara Virgine, de tempore necnon de sanctis, Andrea Poletti, 1745, cap. XVI, f. 92. | ${ }^{6}$ Cita no localizada.

as. oprobrobrium.

56va.: Sed sunt quidam qui remanent et non sequuntur Christum cum istis ramis, sed manent cum iudeys cum ramis de salicibus infructuosis et sahuc fetidis et spinis pungitivis animas eorum. Et isti sunt protervi qui nullo modo bona volunt exercere ut salices sed opera carnalia fetida, ut sahuc, et mundana tamquam raptores ut romagueres. Unde «Protervitas est duricies mentis et perversitas faciendi bonum et audiendi ${ }^{1}$. Ita quod isti tales remanent cum iudeis protervis qui nullo modo volunt sequi Christum, quod est signum reprobacionis. Unde II a ad Thymotheum IIIo: «In novissimus diebus instabunt tempora periculosa [et] erunt homines se ipsos amantes cupidi, elati, superbi, [blasphemus], parentibus non obedientes, ingrati [scelesti, sine affectione,] sine pace, criminatores [incontinentes, inmites,] sine benignitate proditores, protervi [, tumidi,], voluptatium amatores magis quam Dei $»^{2}$. Ecce protervitas quod facit istos remanere cum iudeis protervis et tandis et non sequuntur Christum pauperem et humilem.

${ }^{1}$ Sancti Bernardíni Sienensis commentarii in Apocalipsim, cap. XVI, f. $\left.92\right|^{2} 2$ Tim. 3, 1-2.

56v.: iudey qui Christi Ihesu erant capitales inimici continue ei parabant insidias nunc occulte nunc apperte. Et hoc ut ipsum posent interficere quis finis eorum erat iste, et tamen Christus erat de genere eorum (...) 
Vos Christe invenietis iudeos concordes in malicia contra vos et hoc propter eorum opera mala, ymmo pessima. lam enim isti captivi a dyabolo tenebantur. Crede quod de ista adversitate iudeorum contra Christum iam presenciebat ipsa beatissima Virgo Maria. Et licet Christus hodie fuerit receptus ut rex tamen ipsi ribaldi maoires eum habebunt valde odio. Ideo maledicti perseverant. Unde Ysaie XLVo: "Ve qui contradicit factori suo» ${ }^{1}$.

(...) Crimen committerent lesa maiestatis vassallus alicuius regis cum hostes intra urbem iuvat armis vel pecucia vel consilio vel provincias subiectas nititur facere rebelles vel movet sedicionem in populo, civitatis, vel qui occidunt magistratum vel principem. Et in ista parte iudey comiserunt crimen lese maiestatis. Sapiencie IIo: "Venite, dixerunt inpii ${ }^{2}$ » et cetera. Vel qui levaret astam, ensem vel gladium vel lapidem proiceret contra suum dominum. Hec omnia iudey contra Christum fecerunt ut patet intuenti. Unde leremie Lo: "Contra Deum erecta est et adversus Sanctum Israel ${ }^{3}$ ", scilicet, multitudo et congregacio iniquorum iudeorum. Et hoc continue contra omnia $\left.\right|^{\text {57ra. }}$ Christi opera.

1. Is. $45,9 .\left.\right|^{2}$ Cf. ler. 18, 18-23. | ${ }^{3}$ ler. 50, 29.

57r.: Unde perfidia est animi incredulitas nolens acquiescere veritati sed contradicere, sicud iudey faciebant Christo, ei continue contradicendo.

59v.: Inpugnacio blasfemativa. Unde Hugo: «Blasfemia est imposicio sine vituperium illatum alicui quod ei non convenit cum quadam reverencie ${ }^{1}$. Sicud fecerunt iudey contra Christum dicentes quod miracula faciebat in virtute demonis vel quia erant parva.

\section{${ }^{1}$ Cita no localizada.}

61v.: Secundo principaliter ostenditur affeccio unitiva quia patrem meum. Certum est quod illa est affeccio unitiva quod unit et ligat in concordia vera duas voluntates. Sed patrem honorare hoc facit. Sequitur quod erit affeccio unitiva. Et hoc est in evangelio hodierno. In quo multa sunt que ad duo reduci possunt principaliter:

Primo exercicium directivum.

2o iudeorum maleficium inpugnativum,

Primo ergo est Christi exercicium directivum. Unde quia iudey Christi exercicium et doctrinam maliciose inpugnabant et eum diffamabant dixit eis: "Quis ex vobis arguet me de peccato» ${ }^{1}$. Dicat modo venerat peccata curare et ex super habundanti humilitate subiciebat se examini. Et quia nullum habea dico veritatem et non creditis. Nam «Qui es Deo verba Dei audit, propterea vos non audits quia ex Deo non estis ${ }^{2}$. Quod tamen est signum reprobacionis, non audire verbum Dei nec pati correccionem nec correctorem. Et ecce exercicium directivum.

20 est iudeorum maleficium inpugnativum. "Nonne bene dicimus nos quia samaritanus es et demonium habes» ${ }^{3}$ quia erant victi racione dicebant blasfemias samaritanus conversus de gentilitate vel custos. Ideo solum dixit: "Ego demonium non habeo, sed honorifico Patrem meum ${ }^{4}$ per opera «Ego non quero propriam gloriam» ${ }^{5}$. "Si quis sermonem ${ }^{6}$ et cetera. Tunc iudey: "Nunc cognovimus» ${ }^{7}$ et cetera. Tunc Ihesus: «Si ego glorifico me ipsum gloria mea nichil est ${ }^{8}$, scilicet, maniter et cetera, quia in paupertate vino et solum quero profectum animarum. Dixerunt iudey: "Quinquaginta annos»" et cetera, et Christus: "Antequam Abraham fieret ego sum. Tulerunt lapides [...] et ipse exivit de templo» ${ }^{10}$. Unde primo Regum ॥o: "Quicumque honorificabit me glorificabo eum»" Ideo "Honorifico patrem meum». Hic per graciam et in futuro per gloriam. Amen.

${ }^{1}$ Io. $8,46 . \mid{ }^{2}$ Io. $8,47 . \mid{ }^{3}$ lo. $8,48 . \mid{ }^{4}$ Io. $8,49 . \mid{ }^{5}$ Io. $8,50 . \mid{ }^{6}$ Io. 8, 51. $\left.\right|^{7}$ |o. $8,51 .\left.\right|^{8}$ Io. $8,54 . \mid{ }^{9}$ Io. $8,57 . \mid{ }^{10}$ Io. 8, 58-9. $\left.\right|^{11} 1$ Sam. $2,30$.

76r.: anima infecta malicia totaliter devia est ab omni rectitudine necessaria ad salutem eternam obtinendam. Vere huic veneno potest reperiri tryaca. Unde Crisostomus super lohanem: "Hodie malicie nullum est remedium quia est temporaneus demon ebrietate, dificilior demone, misereabilior aliis malis, detestabilior cunctos inficit et se interficit ${ }^{1} »$. Hac infecti fuerunt iudey ceci devii totaliter a rectitudine racionis et a via veritatis. Unde loelis IIIㅇ: "Multiplicatu est malicia populi $\mathrm{mei}^{2}$ ». Ideo dixerunt Christo qui ipsos racione clara confundebat: Nostras manus non evades quia "demonium habes ${ }^{3}$ », lohanis VIII capitulo originaliter et in evangelio hodierno. Ecce ergo tanta est vis malicie quod adhuc iudey non sunt curati de eius infeccione nec fideles possunt curari nisi cum maxima et obtima triaca gracie que est sanguis Christi, quam nobis procurat illa que nunquam fuit infecta. Ideo ad ipsam recurramus humili mente ac pia dicendo: Ave Maria...

${ }^{1}$ Cf. Iohannes Chrysostomus, Homiliae in Iohanem, Hom. 48, PG 59, 273: "Iram inter et furorem nullum discrimen; sed temporarius quidam daemon est, imo daemoniaco pejor". Cf. Tomás de Aquino, Summa Theologica, $\|$ II , q. 158 a. 4 arg. 2: "Irae et insaniae nihil est medium, sed ira temporaneus est quidam Daemon, magis autem et Daemonium habente difficilius". | ${ }^{2} \mathrm{Cf}$. loel 3, 13. | ${ }^{3}$ lo $8,48$.

77r.: ipsi iudey verbum Dei nolebant audire, quod est signum reprobacionis.

77r.: moti malicia que mentem eorum excecavit dixerunt Christo...

81v: Prima ergo hora est congregativa. Ecce quod omnes inimici Christi fecerunt manipolum moti malicia ut Christum interficiatur. Ecce quod non dubitant comitere crimen lese maiestatis tractando mortem Dominum sui. Unde Psalmos IIo: "Principes convenerunt in unum adversus Christum principes dyabolici» ${ }^{1}$, scilicet, sacerdotales et temporales convenerunt ut Christum interficiant dicentes, Sapiencie II: Venite dixerunt impii apud semetipsos non recte cogitantes, «Opprimamus [pauperem] iustum et circunveniamus eum quoniam inutilis est nobis et contrarius est operibus nostris, abstinet se a viis nostris tanquam ab inmundiciis, inproperat nobis peccatis legis et filium Dei se nominat, sit fortutudo nostra lex iusticie. Morte turpissima condempnemus eum. Hec cogitaverunt et erraverunt. Excecavit illos malicia eorum et nescierunt sacramenta Dei ${ }^{2}$. Unde Luce XXIIo: "Hec est hora nestra et potestat tenebrarum ${ }^{3}$ », id est, malicia vos excecavit. Ideo in vobis habet potestatem. Et hec est prima hora congregativa. Ideo Christus nobiscum non maneat quia venit hora ut transeat, et sic sunt congregati. 
2a hora est consiliativa. In hac hora celebratur consilium ut Christus moriatur. Et sunt inter ceteros ibi quatuor pessimi homines:

Primo ludas proditor et parte symoniacorum.

2o Pilatus ex parte tyranorum.

Tercio Cayphas ex parte impiorum.

4ㅇ Anna ex parte hereticorum.

Et primo loquitur proditor latro ludas. Mathei XXVI: "Quid vultis michi dare et ego etum vobis tradam» ${ }^{4}$. Iste est ex parte simoniacorum qui comedum de mensa Christi et vendunt eum et eius dona. Unde leremie XIo: "Dilectus meus in domo mea fecit scelera multa ${ }^{5}$ ", «Et ego quasi agnus qui portatur ad victimam et ipsi super me cogitaverunt consilium dicentes. Venite, mittamus lignum in panem eius et eradamus eum de terra vivencium et nomen eius nom memoretur amplius ${ }^{6}$. Ad literam de Christo. Nam possuerunt lignum, scilicet, crucem.

2 ㅇ est ibi Pilatus ex parte tyranorum ne perdat dominium. Unde Ezequielis XXIIIO: «Congregabo adversum

${ }^{1}$ Ps. 2, 2. $\mid{ }^{2}$ Cf. Sap. $2,12-21 . \mid{ }^{3}$ Lc. $22,53 . \mid{ }^{4}$ Mt. $26,15 . \mid{ }^{5}$ ler 11, 15. $\mid{ }^{6} \mathrm{Cf}$. ler. $11,19$.

120r.: propter eorum infirmatatem que est lepra leprosi enim sunt infecti, despecti, eiecti, subiecti. Lepra enim est malum cangafistum facit corpus fetidum, et inmndum. Est eciam infirmitas incurabilis, sic recte quilibet peccator dicitur leprosus (...) Sicut lepra non potest curari per naturalem medicinam, ita nec istud peccatum non remittitur nisi per maximam dei clemenciam (...) Qui intelligir opera Dei et ex malicia contradicit et opera spiritus sancti dicit Belzebuc est non habet remissiones neque hic neque in futuro quia dignere penitere non potest. Nisi hoc fiat ex habundante gracia preceptoris. Ideo debet fieri invocacio magne clemencia dicendo Ihesu preceptor: Miserere nostri.

$\mathrm{Si}$ recte volumus videre omnem omnia inpedimenta removere et tunc videbimus deus mirabilia quia remotis impedimentis que necesario habunt removere tunc videtur res sicuti est et intellectus tunc verum certe affirmat et falsum negat, hoc per hiis divine gracie penitenciam quam nobis procurat dulcissima mater Dei.

120v.: "Invidia cuncta bona terminat et pestifero veneno devorat et sensum comedit, pectus urit, mentem inficit et cor hominis quasi quedam pestis depastitur ${ }^{1}{ }^{1}$. Indivia enim peccatum est dyabolicum omnes, ergo invidi dyabolo conparantur. Unde Sapiencia IIo: «Inmundia dyaboli mors intravit in orbem terrarum imitantur illum qui sunt ex parte illius ${ }^{2}$, scilicet, invidie et tunc gloriantur cum malefecerint et exultant in rebus pessimis quorum vie perverse sunt.

${ }^{1}$ Bernardus Claraevallensis, Tractatus de interiori domo seu de conscientia aedificanda, caput 23, PL 184, 553. | 2 Sap. 2, 23-24.

140ra.: Secundo est operacio ingratitudo quia fuerunt ingrati iudei propter quatuor:

Primo quia receperent fructus.

2 quia vituperaverunt nuncios Dei.

3ㅇ quia occiderunt prophetas.

4ㅇ quia occiderunt Christum, ut dicitur actum VIII․

141ra.: Blasffemia simulata in hoc quia pharisey blasffemabant Christum modo simulato dicentes "Quanta audivimus ${ }^{1}$. Non dixerunt 'scimus' que alibi facis fac hic in patria tua. Quia illa que dicunt vel non sunt vera vel tu non es potens facere miracula ubique, quia si posses hic faceres, ut honorem a tuis haberes, vel illa facis per incantaciones demonum. Unde Ysaia Vo: «Abiecerunt legem Dei et eloquium sancti Israel blasffemaverunt $»^{2}$.

Secundo est potencia ligativa ex parte iudeorum. Nam quia Christus ibi nolebat facere miracula era indevocio eorum et incredulitas. Et hoc probat Christus per exempla. Nam tempore famis Elyas non fecit miraculum iudeis sed vidue gentis aliene de farina et oleo, et hoc propter iudeorum incredulitatem. Unde Beda: «Sicut tempore famis, nemo in ludea fuit repertus dignus hospicio et signo Helye, sed exterae ${ }^{a}$ gentis vidua ${ }^{3}$. Ita et vos iudei qui me spernitis superno, nunc privati estis miraculorum.

Tercio est malicia dampnata quia| ${ }^{141 r b}$ nolebant eum precipitare Yhesus autem transiens per medium illorum venit ad nos, hic per graciam et in futuro per gloriam. Amen.

${ }^{1}$ Ps. 77, 3. $\mid{ }^{2}$ Is. 5, 24. $\mid{ }^{3}$ Beda, In Lucae evangelium expositio. PL $92,376 \mathrm{C}$.

${ }^{a}$ Ms. extranee.

144ra.: lam declaratum est quod ad perfectam satisfaccionem culpe necessarium est adiutorium Christi ad nos mundandum, qui sanat omnes nostras infirmitates. Nam Apocalipsis primo: «Dilexit nos et lavit nos a peccatis nostris in sanguine suo, sanando omnes nostras infirmitates et vulnera». Et hoc est quod dicitur in evangelio hodierno: «Sanum feci totum hominem». Ioannis VIIo capitulo originaliter

145va.: Nam illi qui volunt converti continue insidiantur ut obviare possint volentibus converti ad Deum. Et hoc facit perfidia, de qua in evangelio dicemus contra iudeos que 145vb. provenit ex malicia cordis, duricia et presumpcione. Unde perfidia est animi incredulitas nolens acquiescere veritati sed contradicere. Sed illi qui non sunt perfidi et attendunt ad eorum peccata et ad Christi Ihesum clemencia accedunt cum Martha et Magdalena ad pedes eius dicendo: "Miserere mei Deus quoniam si hic fuisses frater meus non fuisset mortuus» ${ }^{1}$. Et hec est clamacio vigorosa quod fuit prima principalis.

${ }^{1}$ Io. $11,21$.

146vb. Primo ergo est malignitas furiosa, scilicet iudeorum, quia propter invidiam nolebant eum capere. Unde Crisostomus: "Solucio sabbati non fuit tota causa odium sed invidia quia turbe eum laudabant ${ }^{1}$. ideo ipsum persequebantur.

${ }^{1}$ Cita no localizada.

147r.: Nam murmurabant ali qui Christum diffamando dicentes: 'Quia malus est'. Alii dicebant: 'Non, sed quia bonus est'. Unde Mathei IXo: «Diffamaverunt eum in totam terram». Et hoc propter maximam invidiam et ipse dat hic graciam et in futuro gloriam. Amen.

${ }^{1}$ Mt. 9, 31. 
147v.: Primo est vita bestialis quam iudei sequebantur credentes posse Christum decipere et «Circumdederunt eum dicentes: [Quousque animam nostram tollis? Si tu es Christus, dic nobis pallam]» ${ }^{1}$. Et tamen videbant signa et non convertebantur. Unde Augustinus: "Non veritate desiderabant sed calumpniam preparabant $»^{2}$. Calumpnia vero erat quia si dixisset 'Ego sum Christus', accusassent eum Cesari quod se regem faciebat ${ }^{3}$. Si autem negasset in sequela eius populum retraxissent. «Erat yems et ipsi frigidi erant $»^{4}$.

(...)Tercio est vita dyabolicalis. Iudeorum in hoc quia inpungnabant veritatem cognitam.

\footnotetext{
${ }^{1}$ Augustinus Hiponensis, In evangelio lohannis tractatus centum viginti quatuor, omelia 48, PL 35, 1741. $\left.\right|^{2}$ Idem. $\left.\right|^{3}$ Cf. Ibid. PL 35, 1742. | ${ }^{4}$ Ibid. PL 35, 1741.

148rb.: iudeorum sacerdotum qui collegerunt consilium ut interficerent Christum. Unde Augustinus: «Plus homines perditi cogitabant quomodo eum perderent, quam quomodo anime sue consulerent ut converterentur ${ }^{1} »$.

Secundo est malignitas venenosa ut homicidium conmittant et crimen lese magestatis | ${ }^{148 v a}$. et sacre legum prophetavit Cayfa, scilicet. Unde Origenes: «Sicud aliqui bono male utuntur ita isti propheta pro salute humani generis et ita male percipientes consiliati sunt occidere Christum ${ }^{2}$.
}

\footnotetext{
${ }^{1}$ Augustinus Hiponensis, In evangelio lohannis tractatus centum viginti quatuor, tractatus 49 , cap. 26 , PL 35, 1757. | ${ }^{2}$ Cita no localizada.
}

\section{BIBLIOGRAFIA}

Abulafia, A. S. (ed.) 2002. Religious violence between Christians and Jews. Medieval roots, Modern perspectives. Nueva York - Londres: Palgrave publishers.

Abulafia, D. 1992. "From privilege to persecution: Crown, Church and Synagogue in the City of Majorca, 1229-1343», in D. Abulafia, M. Franklin and M. Rubin (eds.), Church and City, 1000-1500: 111-26. Essays in honour of Christopher Brooke. Cambridge: University Press.

Adams, J. 2014. "Preaching about an absent minority. Medieval Danish sermons and Jews" en J. Adams, J. Hanska (eds.), The JewishChristian Encounter in Medieval Preaching: 92-116. Nueva York Londres: Routledge.

Algaida, S. d', 1931. "Tres sermons de Bartomeu Catany, framenor de Mallorca (s. Xv). Estudis Franciscans 43: 408-421.

Alonso, M. (ed.). 1943. Alonso de Cartagena, Defensorium unita tis christianae. Madrid: Publicaciones de la escuela de estudios hebreos.

Baer, Y. 1981. Historia de los judíos en la España cristiana, vol. 1. Madrid: Altalena.

Ben-Aryeh, D. N. 2001. Renaissance Florence in the rhetoric of two popular preachers: Giovanni Dominici (1356-1419) and Bernardino de Siena (1380-1444). Brepols: Turnhout.

Biosca, A. 2004. "Propaganda religiosa en la carta de Samuel», en Barrio Barrio, J. A. (ed.). Los cimientos del Estado en la Edad Media: cancillerías, notariado y privilegios reales en la construcción del Estado en la Edad Media: 319-324. Alcoy: Marfil.

Braunstein, B. 1976. Els xuetes de Mallorca. Barcelona. Curial.

Bravo Lledó, P. y Gómez Vozmediado, M. F. 1999. «El alborayque. Un impreso pamfletario contra los conversos fingidos de la Castilla bajomedieval». Historia, instituciones, Documentos, 26: 57-83.

Campanini, S. (ed.) 2004. The book of Bahir. Flavius Mithridates Latin Translation, the Hebrew Text, and an English Version. Torino: Nino Aragno Editore.
Caro Baroja, J. 1961. Los judíos en la España moderna y contemporánea, vol. II. Madrid: Arión.

Catalán, O. 2013. La predicació Cristiana a la Catalunya baixmedieval. Tesis de doctorado inédita. Barcelona: Universidad de Barcelona.

Cátedra, P. 1994. "La modificación del discurso religioso con fines de invectiva. El sermón». L'invective au Moyen Âge. France, Espagne, Italie, Atalaya, 5: 101-122.

Cohen, J. 1982. The friars and the Jews. Ithaca: Cornell, Cornell University Press.

Cohen, J. 1996. From witness to witchcraft: Jews and Judaism in Medieval Christian Thought, Wiesbaden. Harrassowitz.

Colom, M. 1992. "L'origen dels conversos mallorquins» en Id., La Inquisició a Mallorca (1488-1578). Barcelona: Curial.

Copeland Klepper, D. 2000. «Nicholas of Lyra and Franciscan interest in Hebrew Scholarship», in Nicholas of Lyra: the senses of Scripture: 289-311, ed. P. D. W. Krey and L. Smith. Leiden: Brill.

Cuadrado, J. M. 1847. Forenses y ciudadanos. Historia de las disensiones políticas de Mallorca en el siglo XV. Palma de Mallorca: Imprenta y librería de D. Estevan Trias.

Debby, N. 2014 "Mendicants and Jews in Florence», en J. Adams, J. Hanska (eds.), The Jewish-Christian Encounter em Medieval Preaching: 282-295. Nueva York - Londres: Routledge.

Edwards, J. 1984. "Mission and Inquisition among Conversos and Moriscos in Spain, 1250-1550», en Persecution and Toleration; Papers Read at the 22nd and the 23rd Meeting of the Ecclesiastical History Society: 139-151. Ed. W. J. Sheils. Oxford: Basil Blackwell.

Espina, A. de. 1485. Fortalitium fidei. Nurenberg.

Fernández Gallardo, L. 2002. Alonso de Cartagena 1385-1456: una biografía política en la Castilla del siglo xv. Valladolid: Junta de Castilla y León.

Fidora, A. 2013. «Ponç Carbonell and the early Franciscan reception of the Pugio Dei». Medieval Encounters 19: 567-585.

Furió, A. 1851. Vida del bendito padre fray Bartolomé Catany. Palma de Mallorca: Imprenta a cargo de D. Juan Guasp.

Gay-Canton, R. 2010. "Lorsque Muhammad orne les autels». Révue des sciences philosophiques et théologiques, 94-2: 201-248.

García-Jalón de la Lama, S. y Reinhardt, K. (eds.) 2006. La disputa de Abutalib. Madrid: Aben Ezra ediciones.

Gerli, E. M. 2007. "The converso condition: New Approaches to an Old Question», I. A. Corfis and R. Harris-Northall (eds.). Medieval Iberia: Changing Societies and Cultures in Contact and Transition, CT, A247: 3-15. London: Tamesis.

Gitlitz, D. 1992. «Hybrid conversos in the Libro llamado el Alboraique». Hispanic Review 60: 1-17.

Gow, A. C. 1995. The red Jews. Antisemitism in an Apocalyptic age. 1200-1600. Leiden: Brill.

Hames, H. J. 1998 «Ramon Llull y su obra polémica contra los judíos» en La controversia judeocristiana en España. Homenaje a Domingo Muñoz León: 317-344. Madrid: CSIC.

Hillgarth, J. N. 1991. Readers and books in Majorca, 1229-1550. París. C.N.R.S.

Huerga, P. 1994. En la raya de Portugal: solidaridad y tensiones en la comunidad judeoconversa. Salamanca: Universidad de Salamanca.

Hughes, D. 1986 «Distinguishing signs: ear-rings, Jews and Franciscan Rhetoric in the Italian Renaissance City", Past \& Present, 112: 3-59.

Ingram, K. (ed.) 2009. The Conversos and Moriscos in Late Medieval Spain and Beyond. Leiden: Brill.

Klaus Reinhardt (eds.) 2006. La disputa de Abutalib. Madrid: Aben Ezra ediciones.

Lazar, M. «Anti-Jewish and Anti-Converso Propaganda: Confutatio libri Talmud and Alboraique», en Lazar, M.; Haliczer, S. (eds.). The Jews of Spain and the Expulsion of 1492: 207 - 219. Lancaster: Calif.

Lea, H. 1983. Historia de la inquisición española, vol II. Madrid.

Limor, A. 1996. «The epistle of Rabbi Samuel of Morocco: A Best-Seller in the World of Polemics", en Limor, A.; Stroumsa, G. (eds.), Contra iudaeos. Ancient and Medieval Polemics Between Christians and Jews: 177-194. Tübingen: Mohr. 
López Martínez, N. 1954. Los judaizantes castellanos y la inquisición en tiempo de Isabel la Católica: 379-382. Salamanca. Universidad Pontificia.

López Martínez, N. y Proaño, V. (eds.) 1957. Torquemada, Juan de. Tractatus contra madianitas et ismaelitas adversarios et detractores filiorum qui de populo israelitoco originem traxerunt. Burgos. Seminario Metropolitano.

Losada, C. 2013. "Ley divina y ley eternal: antijudaísmo y estrategias de conversion en la campaña castellana de San Vicente Ferrer (1411-1412). Hispania Sacra, LXV: 603-640.

Llompart, G. 1988. "La catedral de Mallorca como centro difusor de teatro popular». Revista de dialectología y tradiciones populares 43: 361-2.

Llompart, G. y Riera J. 1979-80. «La historia de Sancta Fide Catholica de Benet Espanyol (1548). La primera historia dels jueus de la ciutat de Mallorca». Fontes rerum balearium 3: 141-194.

Luzzati, M. y Galasso, C. 1996. «Primi appunti su Girolamo Savonarola e gli ebrei dello stato fiorentino», en Garfagnini, G. C. (ed.), Studi Savonaroliani: 35-41. Florence.

Maiz Chacón, J. 2010. Los judíos de Baleares en la Baja Edad Media: economía y política. Palma de Mallorca: Netbiblo.

Massip, F. 2007. Història del teatre català: 112. Tarragona: Arola.

Meyuhas Ginio, A. 1998. De bello iudaeorum: Fray Alonso de Espina y su «Fortalitium fidei». Salamanca: Universidad Pontificia.

Monsalvo Antón, J. M.a 1994. «Mentalidad antijudía en la Castilla medieval. Cultura clerical y cultura popular en la gestación y difusión de un ideario medieval», en Barros, C. (ed.), Xudeos e conversos na Historia: vol. I: 21-84. Santiago de Compostela.

Monsalvo Antón, J. M.a 2012. "Los mitos cristianos sobre crueldades judías y su huella en el antisemitismo medieval europeo», en García Fernández, E. (ed.), Exclusión, racismo y xenofobia en Europa y América: 13-87. Bilbao.

Mormando, F. 1999. The preacher's demons. Bernardino of Siena and the Social Underworld of Early Renaissance Italy. Chicago: University of Chicago Press.

Morro Veny, G. 1997. Mallorca a mitjan segle xv: el Sindicat i l'alçament forà. Palma de Mallorca: Documenta Balear.

Morro Veny, G. 2008. Bartomeu Catany. Un teòleg al servei del compromís i la concòrdia. Palma de Mallorca: Ajuntament.

Muzzarelli, M. G. 2014. «The effects of Bernardino da Feltre's preaching on the Jews", Jewish-Christian encounter in medieval preaching: 170-194.

Myers, S. E. y MacMichael, S. J. (eds.) 2004. The friars and Jews in the Middle Ages and Renaissance. Brill: Leiden.

Netanyahu, B. 2005. De la anarquía a la Inquisición: estudios sobre los conversos en España durante la Baja Edad Media. Madrid: Esfera de los libros.

Neuman, A. 1969. The Jews in Spain. Their Social, Political and Cultural Life during the Middle Ages, t. 1, New York

Nirenberg, D. 2000. «El concepto de raza en el estudio del antijudaísmo ibérico medieval». Edad media: revista de historia 3: 39-60.

Nirenberg, D. 2008. «Race and the Middle Ages: the case of Spain and the Jews» en M. R. Greer, W. D. Mignolo, M. Quilligan (eds.), Rereading the Black Legend: The Discourses of Religious and Racial Difference in the Renaissance Empires: 71-87. University of Chicago Press.

Nirenberg, D. 2014. Neighboring faiths. Christian, Islam and Judaism in the Middle Ages and Today. University of Chicago Press.

Orfali, M. 2012. «La prédication chrétienne sur les Juifs dans I’Espagne du bas Moyen Âge». Révue de l'histoire des religions, 229-1: 31-52.

Pérez Martínez, L. 1955. Misión apostólica de San Vicente Ferrer en Mallorca (1413-1414). Palma de Mallorca: Tipografía Guasp.

Prats, F. 1985. Llibre de contemplació. Palma de Mallorca: Miquel Font editor.

Ribera Florit, J. 1967. La polémica cristiano-musulmana en los sermones del maestro inquisidor Don Martín García. Barcelona: Universidad de Barcelona.
Riera, J. 1982. «Contribució a l'estudi del conflicte religiós dels conversos jueus». IX congresso di storia della Corona d'Aragona: 409-425, vol. II. Nàpoles.

Riera, J. 1989. "Literatura antijueva en català: textos i difusió». Estudi general 9: 215-236.

Riera, J. 1993. "Judíos y conversos en los reinos de la Corona de Aragón durante el siglo XV», en La expulsión de los judíos de España. II curso de cultura hispano judía y sefardí: 71- 91. Toledo: Asociación de Amigos del Museo Sefardí.

Riera Montserat, F. 1973. Lluites antixuetes en el segle XVIII. Palma de Mallorca: Moll.

Roest, B. 2014. Franciscan Learning, Preaching and Mission c. 12201650. Leiden: Brill.

Rosselló i Vaquer R. y Murillo i Tudurí, A. 1990. Els jueus dins la societat menorquina del segle XIV. Menorca: Institut d'Estudis Baleàrics Institut d'estudis menorquins.

Rosselló Lliteras, J. 1987. «San Vicente Ferrer: su misión en Mallorca (1413-1414)», Boletín de la Sociedad Arqueológica Luliana 43: 71-84.

Roth, N. 2002. Conversos, Inquisition, and the expulsion of the Jews from Spain. University of Wisconsin Press.

Rubió, J. 1990. «El beat fra Mateu d'Agrigento a Catalunya i a València: notes sobre la vida religiosa en una cort del Renaixement», en Id., Humanisme i Renaixement. Montserrat: PAM.

Sanahuja, P. 1959. Historia de la Seráfica Provincia de Cataluña. Barcelona: Ed. Seráfica.

Santamaría, Á. 1955. "En torno a la situación de los judíos conversos de Mallorca en el siglo XV». Boletín de la Sociedad Arqueológica Luliana 31: 185-97.

Santamaría, Á. 1974. «Los judíos conversos de Mallorca», en Mascaró Passarius, Història de Mallorca, vol. V: 394-404.

Santamaría, Á. 1975. "La instauración de la nueva Inquisición en Mallorca», en Homenaje al Dr. D. Juan Reglà Campistol vol. I: 173187, Valencia, Universidad.

Santamaría, Á. 1997. "Sobre la condición de los conversos y chuetas de Mallorca». Espacio, Tiempo y Forma. Serie III, Ha Medieval 10: 219-261.

Sedda, F. 2014. "The Anti-jewish sermons of John of Capistrano: Matters and context», en J. Adams, J. Hanska (eds.), JewishChristian encounter in medieval preaching. Routledge. New York - London.

Seidenspinner-Núñez, D. 1996. "Inflecting the converso voice». La Corónica, 25.1: 6-18.

Sicroff, A. 1969. Les controverses des statuts de 'Purété de sang' en Espagne du XVe au XVII siècle. Paris: Didier.

Soyer, F. 2014. Popularizing Anti-Semitism in Early Modern Spain and its Empire. Francisco de Torrejoncillos and the Centinela contra judíos (1674). Leyden: Brill.

Verdin Diaz, G. 1992. Alonso de Cartagena y el Defensorium Unitatis Christianae: introducción histórica, traducción y notas. Oviedo: Universidad de Oviedo.

Vidal, R. 2013. "'Nos soli sumus christiani': conversos in the texts of the Toledo rebellion in 1449», en Medieval Hispanic Studies in Memory of Alan Deyermond: 215-236. Londres: Tamesis Books.

Villanueva, J. 1852. Viage literario a las iglesias de España, vol. 22. Madrid: Real Academia de la Historia.

Zeldes, N. 2009. «Sicilian converts after the Expulsion: Inter-community relations, Acculturation and the Preservation of group Identity", en The Conversos and Moriscos in Late Medieval Spain and Beyond: Departures and change. Leiden: Brill.

Zozaya, L. 2009. «A thorn in the community: popular religious practice and converso dissidence in the district of Molina de Aragón», en The conversos and moriscos in late Medieval Spain and Beyond: 161-186. Leyden: Brill. 